This PDF is a selection from a published volume from the National Bureau of Economic Research

Volume Title: Preventing Currency Crises in Emerging Markets

Volume Author/Editor: Sebastian Edwards and Jeffrey A.

Frankel, editors

Volume Publisher: University of Chicago Press

Volume ISBN: 0-226-18494-3

Volume URL: http://www.nber.org/books/edwa02-2

Conference Date: January 2001

Publication Date: January 2002

Title: Living with the Fear of Floating: An Optimal Policy Perspective

Author: Amartya Lahiri, Carlos A. Végh

URL: http://www.nber.org/chapters/c10646 


\title{
Living with the Fear of Floating An Optimal Policy Perspective
}

\author{
Amartya Lahiri and Carlos A. Végh
}

\subsection{Introduction}

It has long been recognized that "pure" floating exchange rate regimes (defined as regimes in which the monetary authority does not intervene at all in foreign exchange markets) have rarely - if ever-existed in practice. More surprising, however, is the extent to which developing countries (which claim to be floaters) are reluctant to let the nominal exchange rate fluctuate in response to shocks, as convincingly documented by Calvo and Reinhart (2000a). ${ }^{1}$ To assess this phenomenon, consider, as a benchmark for a relatively pure floater, the cases of the United States and Japan. As indicated in table 14.1, the probability that the monthly variation in the nominal exchange rate falls within a \pm 2.5 percent band is 58.7 percent for the United States and 61.2 percent for Japan. In contrast, for developing countries classified by the International Monetary Fund (IMF) as free floaters (FL) or managed floaters (MF), the average probability is 77.4 percent. This is even more remarkable considering that one would conjecture that developing countries are subject to larger and more frequent shocks. ${ }^{2}$ Thus, the

Amartya Lahiri is assistant professor of economics at the University of California, Los Angeles. Carlos A. Végh is professor of economics at the University of California, Los Angeles, and a research associate of the National Bureau of Economic Research.

The authors would like to thank Joshua Aizenman, Eduardo Borensztein, Jaewoo Lee, Eduardo Moron, and participants at the 2001 AEA meetings in New Orleans and the NBER conference in Florida for helpful comments and suggestions. Both authors gratefully acknowledge research support provided by grants from the UCLA Academic Senate and thank Rajesh Singh for superb research assistance.

1. See also Levy and Sturzenegger (2000). On Peru's experience, see Moron and Castro (2000).

2. As evidenced, for instance, by the fact that real output is between two and two and a half times more volatile in developing countries than in the Group of Seven countries, whereas real 


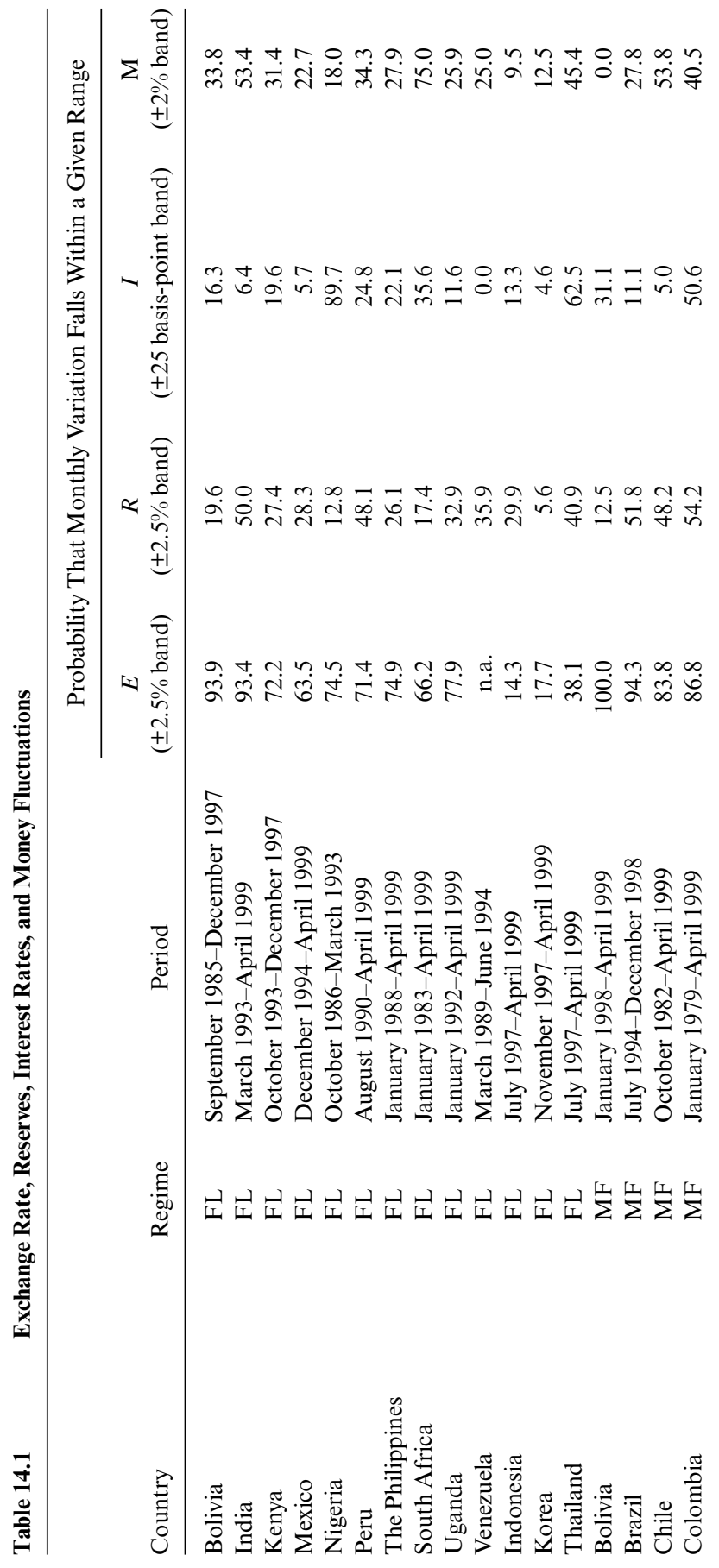




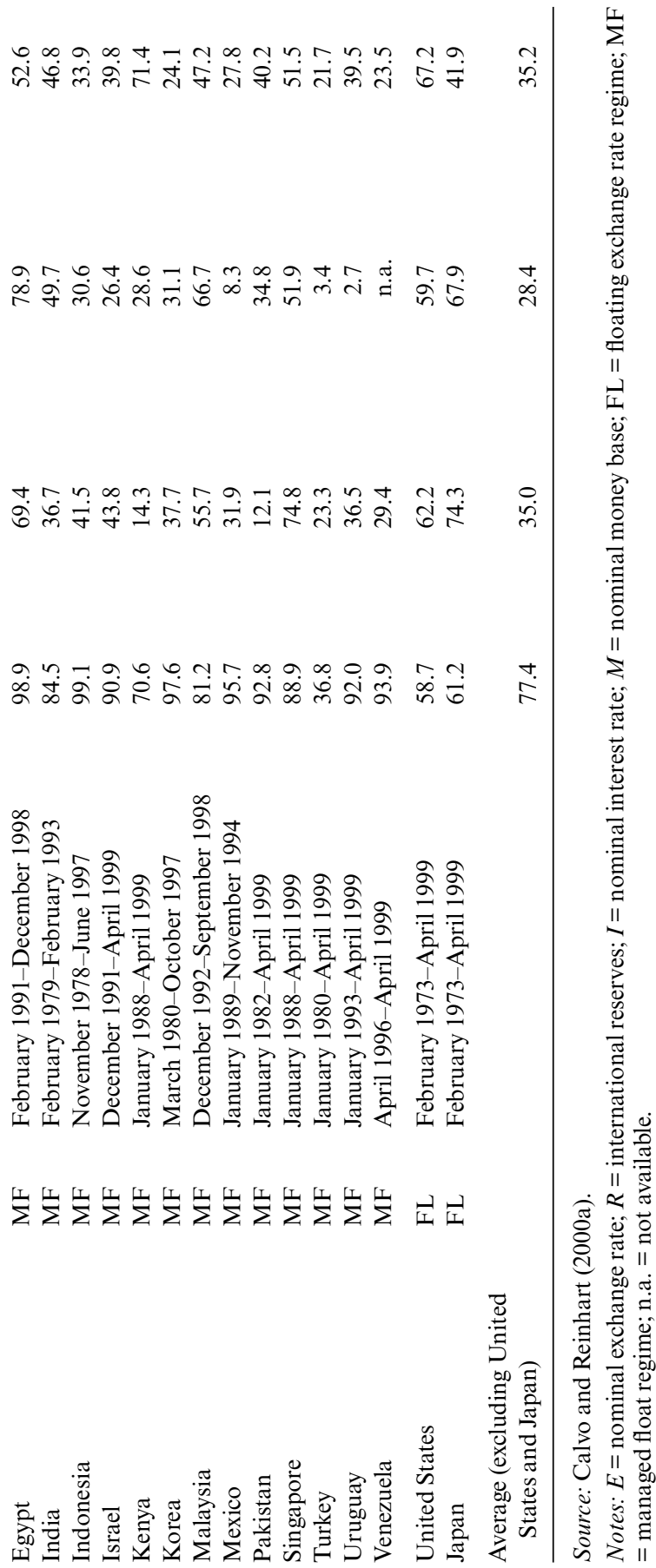


revealed preference for smoothing out exchange rate fluctuations - or "fear of floating"-is nothing short of remarkable.

How do emerging countries smooth out exchange rate fluctuations in practice? Not surprisingly, they do so by actively intervening in foreign exchange markets and engaging in an active interest rate defense of the currency. Again, for the United States and Japan, the probability that the monthly variation in international reserves falls within a \pm 2.5 percent band is 62.2 percent and 74.3 percent, respectively. The corresponding average for developing countries is 35.0 percent, indicating a much larger variability in international reserves. Similarly, the probability that the monthly variation in nominal interest rates falls in a \pm 25 basis point band is 59.7 percent for the United States and 67.9 percent for Japan. The corresponding figure for emerging countries is 28.4 percent, suggesting a much more active interest rate defense of the currency.

In addition, based on contemporaneous correlations among residuals from a vector autoregression analysis for individual episodes, Calvo and Reinhart (2000a) conclude that, in most instances, (a) the correlation between the exchange rate and interest rates is positive, (b) the correlation between reserves and the exchange rate is negative, and (c) the correlation between interest rates and reserves is negative. All three correlations seem to be consistent with the overall story told by table 14.1.

This paper starts from the presumption that the policies just described reflect an optimal policy response to underlying shocks. ${ }^{3}$ In this light, this extreme fear of floating is puzzling because, even if nominal exchange rate fluctuations were costly, one would expect a monotonic relationship between nominal exchange rate variability and the size of the underlying shock (i.e., the larger the shocks, the larger the nominal exchange rate variability). At best, costly exchange rate fluctuations would explain a departure from a pure floating but would not explain the fact that countries subject to larger shocks have less volatile exchange rates, as suggested by the data.

The theoretical challenge is thus to build a simple model that allows for an explicit welfare evaluation of alternative policies and analyze whether the optimal policy in the model roughly replicates the observed policies. This paper represents a first effort on our part to tackle this important question. ${ }^{4} \mathrm{We}$

private consumption is between three and four times more volatile (as shown by Talvi and Végh 2000, based on Hodrick-Prescott filtered data for 1970-94).

3. We consider the main alternative hypothesis (irrational policy makers) to be, by and large, factually wrong, and theoretically uninteresting (as we do not have good theories of irrationality).

4. Naturally, the choice of how much to intervene or raise interest rates in response to a negative shock that tends to weaken the domestic currency is related to the optimal choice of exchange rate regimes. An important literature in the 1980s emphasized the fact that the choice was not limited to the alternatives of fixed versus fully flexible exchange rates, but entailed a decision on the optimal degree of foreign exchange market intervention (with fixed and flexible rates merely being the extreme cases), as captured by the classic contribution of Aizenman and Frenkel (1985). 
develop a simple theoretical model in which, in response to monetary shocks, the optimal policy response replicates most of the key policy facts just described. ${ }^{5}$ In particular, the model predicts that the nominal exchange rate is a nonmonotonic function of the underlying shock (i.e., for small shocks, the nominal exchange rate is an increasing function of the shock, but for large shocks the nominal exchange rate is fully stabilized).

What are the main ingredients of our model? In the model, the fear of floating stems from the fact that exchange rate variability leads to output costs. In the presence of nominal wage rigidities, changes in the exchange rate lead to changes in the actual real wage, which in turn lead to "voluntary unemployment" (to use Barro and Grossman's 1971 terminology) if the real wage falls below its equilibrium value, or to "involuntary unemployment" if the real wage rises above its equilibrium level. (Notice that exchange rate variability is costly regardless of whether the domestic currency depreciates or appreciates. ${ }^{6}$ We model active interest rate defense of the currency along the lines of Calvo and Végh (1995) by assuming that it basically entails paying interest on some interest-bearing liquid asset. ${ }^{7}$ As in Lahiri and Végh (2000b), we incorporate into the model an output cost of raising interest rates. Hence, in our model, higher interest rates raise the demand for domestic liquid assets, but at the cost of a fall in output. Finally, we assume that there is a fixed (social) cost of intervening in foreign exchange markets. ${ }^{8}$

In the context of such a model, consider a negative shock to real money demand. If the shock is small, the output costs entailed by the resulting currency depreciation will also be small. It is thus optimal for policy makers not to intervene and to let the currency depreciate. Because exchange rate fluctuations are costly, however, it is optimal for policy makers to partially offset the shock to money demand by raising domestic interest rates. Hence, for small shocks to money demand, the exchange rate and domestic interest rates move in the same direction, whereas reserves do not change.

If the shock is large (i.e., above a well-defined threshold), the output costs resulting from exchange rate fluctuations would be too large relative to the cost of intervening. It thus becomes optimal to intervene and stabilize the ex-

5. For analytical simplicity, we focus only on monetary shocks. As indicated in table 14.1, monetary aggregates are much more volatile in developing countries, which is consistent with the idea that monetary shocks are larger.

6. We should stress that this is just a convenient analytical way of capturing costs of exchange rate fluctuations. In practice, there may be other (and possibly more important) sources of costly exchange rate fluctuations (see Calvo and Reinhart 2000b). Our focus is on analyzing the resulting optimal policy mix and not on providing sophisticated microfoundations for the cost of exchange rate fluctuations.

7. This paper is therefore related to an incipient theoretical literature that analyzes the active use of interest rates to defend an exchange rate peg (see Drazen 1999a,b; Flood and Jeanne 2000; Lahiri and Végh 2000a,b).

8. Although it is not explicitly modeled, we view this cost as capturing a fixed cost of portfolio adjustment for the private sector when it has to deal with the central bank (in the spirit of asset market segmentation stories in the tradition of Alvarez, Atkeson, and Kehoe [1999]). 
change rate completely. Consequently, there is no need to raise interest rates to prop up the currency. Hence, for large negative shocks, international reserves fall, but the exchange rate and domestic interest rates do not change.

If we think of the real world as involving a sequence of monetary shocks (with developed countries facing mostly small shocks and emerging countries facing mostly large shocks), the model would predict the following. ${ }^{9}$ First, from a cross-sectional point of view, (a) developing countries should exhibit low exchange rate variability and high reserve variability, and (b) conversely, developed countries should exhibit high exchange rate variability and low reserve variability. Moreover, from a time-series point of view (i.e., in individual countries), (c) the correlation between exchange rates and interest rates should be positive, (d) the correlation between the exchange rate and reserves should be negative, and (e) the correlation between interest rates and reserves should be negative. The model thus captures some of the main features of the data described above and should therefore provide a useful conceptual framework for thinking about policy responses in a world in which policy makers live with the fear of floating (i.e., in which nominal exchange rate fluctuations are costly).

The paper proceeds as follows. Section 14.2 develops the model under flexible wages. Section 14.3 introduces sticky wages into the picture. Section 14.4 analyzes the optimal policy mix under costless intervention. Section 14.5 derives the main results of the paper. Section 14.6 concludes.

\subsection{The Model}

Consider a small open economy inhabited by an infinitely lived representative household. The economy consumes and produces two goods, $x$ and $y$, both of which are freely traded. The economy takes the world price of the two goods as given, and the law of one price is assumed to hold for both goods. The foreign currency price of good $y$ is assumed to be constant and, for convenience, normalized to unity. The world relative price of good $x$ in terms of good $y$ is $p$, which is also assumed to be constant over time. The economy has access to perfectly competitive world capital markets where it can borrow and lend freely in terms of good $y$ at the constant world interest rate $r$. Interest parity then implies that $i=r+\varepsilon$, where $i$ is the nominal interest rate and $\varepsilon$ is the rate of devaluation or depreciation.

\subsubsection{Households}

The representative household derives utility from consuming the two goods and disutility from supplying labor. The household's lifetime welfare $(W)$ is given by

9. Our model is nonstochastic, so this characterization of the predictions is based on the comovement of variables in response to a monetary shock. A stochastic simulation of the model is left for future research. 


$$
\begin{gathered}
W \equiv \int_{0}^{\infty} \frac{1}{1-1 / \sigma}\left\{\left[c_{t}-\zeta\left(l_{t}^{s}\right)^{\nu}\right]^{1-(1 / \sigma)}-1\right\} e^{-\beta t} d t \\
\sigma>0, \quad \zeta>0, \quad v>1
\end{gathered}
$$

where

$$
c=\left(c^{y}\right)^{\rho}\left(c^{x}\right)^{1-\rho}
$$

is a consumption composite index (with $c^{y}$ and $c^{x}$ denoting consumption of goods $y$ and $x$, respectively), $l^{s}$ denotes labor supplied by the household, $\sigma$ is the intertemporal elasticity of substitution, $v-1$ is the inverse of the elasticity of labor supply with respect to the real wage (as will become evident below), and $\beta(>0)$ is the exogenous and constant rate of time preference. ${ }^{10}$ In order to rule out secular consumption dynamics, we make the standard assumption that $\beta=r$. Throughout the paper we maintain a notational distinction between labor supply and labor demand because, in the presence of nominal wage rigidities, labor supply will not necessarily equal labor demand at all times.

The household's flow budget constraint in terms of good $y$ (or foreign currency) is given by

$$
\dot{a}_{t}=r a_{t}+w_{t} l_{t}^{s}+\Omega_{t}^{y}+\Omega_{t}^{x}+\Omega_{t}^{b}+\tau_{t}-c_{t}^{y}-p c_{t}^{x}-I_{t}^{d} h_{t}-v\left(\hat{h}_{t} ; \alpha\right),
$$

where $w$ denotes the wage rate in terms of foreign currency (henceforth referred to as the real wage), $I^{d}\left(\equiv i-i^{d}\right)$ is the deposit spread (with $i^{d}$ denoting the interest rate paid on deposits), $\Omega^{y}$ and $\Omega^{x}$ are dividends received from firms in sectors $y$ and $x$, respectively, $\Omega^{b}$ are dividends from commercial banks, $\tau$ denotes lump-sum transfers from the government to households, and $a(=b+h)$ represents net household assets in terms of foreign currency (where $b$ and $h$ denote net foreign bonds and demand deposits, respectively, both in terms of the foreign currency).

Real demand deposits held by the household are denoted by $\hat{h}=H / P$, where $H$ denotes nominal demand deposits and $P$ is the domestic currency price index of the composite consumption good, $c$. Transaction costs incurred by the household are denoted by $v(\hat{h} ; \alpha)$, where $\alpha>0$ is a positive constant. As is standard, we assume that the function $v(\hat{h} ; \alpha)$ is strictly convex in $\hat{h}$ so that $v_{\hat{h}} \leq 0$ and $v_{\hat{h} \hat{h}}>0$. Thus, the household can reduce transaction costs by holding additional demand deposits in terms of the composite consumption good. The parameter $\alpha(>0)$ is a shift parameter for money demand. In particular, we assume that $v_{\alpha}<0$ and $v_{\hat{h} \alpha}<0$. As will be clear below, this implies that money demand, $\hat{h}$, is an increasing function of the parameter $\alpha$.

10. We adopt these preferences for analytical convenience, because they imply that the labor supply decision becomes independent of wealth. Moreover, Correia, Neves, and Rebelo (1995) have shown that these preferences provide a better description of current account dynamics for small open economies than standard constant elasticity of substitution preferences. 
Given equation (2), it is easy to establish that the domestic currency price index is given by

$$
P=\frac{p^{1-\rho}}{\rho^{\mathrm{\rho}}(1-\rho)^{1-\rho}} E \equiv \frac{E}{B},
$$

where $E$ denotes the nominal exchange rate (domestic currency price of the foreign currency), while $B=\left[\rho^{\mathrm{\rho}}(1-\rho)^{1-\rho}\right] /\left[p^{1-\rho}\right]$ is a positive constant. ${ }^{11}$ Since $h=H / E$, equation (4) implies that $\hat{h}=B h$. Hence, transaction costs are given by $v(\hat{h} ; \alpha)=v(B h ; \alpha)$. Since the relative price $p$ is constant over time, it is also easy to see from equation (4) that the rate of inflation must equal the rate of currency depreciation $(\varepsilon)$ at all points in time. Hence, we must have $\dot{P} / \mathrm{P}=\dot{E} / \mathrm{E}=\varepsilon$.

Integrating the household's flow constraint subject to the transversality condition on $a$ gives

$$
\begin{aligned}
a_{0}+\int_{0}^{\infty}\left(w_{t} l_{t}^{s}+\Omega_{t}^{y}+\Omega_{t}^{x}+\Omega_{t}^{b}+\tau_{t}\right) e^{-r t} d t & \\
& =\int_{0}^{\infty}\left[c_{t}^{y}+p c_{t}^{x}+I_{t}^{d} h_{t}+v\left(\hat{h}_{t} ; \alpha\right)\right] e^{-r t} d t .
\end{aligned}
$$

To simplify the analysis, it will be assumed that the transaction costs technology is quadratic. Formally,

$$
v(\hat{h}, \alpha)=\hat{h}^{2}-\alpha \hat{h}+\kappa, \quad \hat{h} \in\left[0, \frac{\alpha}{2}\right],
$$

where $\alpha$ and $\kappa$ are positive constants.

The household chooses time paths for $c^{y}, c^{x}, l^{s}$ and $h$ to maximize equation (1) subject to equations (5) and (6), where $\hat{h}=B h$, and taking as given $a_{0}$ and the paths for $w, \tau, r, p, I^{d}, \Omega^{y}, \Omega^{x}$ and $\Omega^{b}$. The first-order conditions for utility maximization imply that

$$
\begin{aligned}
\rho c_{t}\left[c_{t}-\zeta\left(l_{t}^{s}\right)^{v}\right]^{-1 / \sigma} & =\lambda c_{t}^{y}, \\
(1-\rho) c_{t}\left[c_{t}-\zeta\left(l_{t}^{s}\right)^{\nu}\right]^{-1 / \sigma} & =p \lambda c_{t}^{x}, \\
\nu \zeta\left(l_{t}^{s}\right)^{\nu-1} & =B w_{t}, \\
\alpha-2 \hat{h}_{t} & =\frac{I_{t}^{d}}{B} .
\end{aligned}
$$

Equations (7)-(10) can be used to derive the following relationships:

$$
\frac{1-\rho}{\rho} \frac{c_{t}^{y}}{c_{t}^{x}}=p,
$$

11. $P$ is the consumption-based price index, which is defined as the minimum expenditure required to purchase one unit of the composite consumption index, $\left(c^{y}\right)^{\mathrm{p}}\left(c^{x}\right)^{1-\rho}$. 


$$
\begin{aligned}
l_{t}^{s} & =\left(\frac{B w_{t}}{\nu \zeta}\right)^{1 /(v-1)}, \\
B h_{t} & =\hat{h}_{t}=\frac{\alpha}{2}-\frac{I_{t}^{d}}{2 B} .
\end{aligned}
$$

Equation (11) says that the marginal rate of consumption substitution between the two goods must equal their relative price. Equation (12) shows that households' labor supply is an increasing function of the real wage. Finally, equation (13) says that real money demand in terms of good $y$ must be falling in the opportunity cost of holding deposits, $I^{d}$. Also, for a given $I^{d}$, a higher $\alpha$ implies that $h$ must go up. Hence, the parameter $\alpha$ can be thought of as a shock to money demand.

\subsubsection{Firms}

Since there are two distinct sectors in this economy, there are two types of firms: those that produce good $y$ and those that produce good $x$. Both sectors are assumed to be perfectly competitive. ${ }^{12}$

\section{Sector y Firms}

The industry producing good $y$ is characterized by perfectly competitive firms that hire labor to produce the good using the technology

$$
y_{t}=\left(l_{t}^{d}\right)^{\eta}, \quad \eta \in(0,1],
$$

where $l^{d}$ denotes labor demand. Firms may hold foreign bonds, $b^{y}$. Thus, the flow constraint faced by the firm is

$$
\dot{b}_{t}^{y}=r b_{t}^{y}+\left(l_{t}^{d}\right)^{\eta}-w_{t} l_{t}^{d}-\Omega_{t}^{y} .
$$

Integrating forward equation (15), imposing the standard transversality condition, and using equation (14) yields

$$
\int_{0}^{\infty} e^{-r t} \Omega_{t}^{y} d t=b_{0}^{y}+\int_{0}^{\infty}\left[\left(l_{t}^{d}\right)^{\eta}-w_{t} l_{t}^{d}\right] e^{-r t} d t .
$$

The firm chooses a path of $l^{d}$ to maximize the present discounted value of dividends, which is given by the right-hand side (RHS) of equation (16), taking as given the paths for $w_{t}, I_{t}^{l}, r$, and the initial stock of financial assets $b_{0}^{f}$. The first-order condition for this problem is given by

$$
\eta\left(l_{t}^{d}\right)^{\eta-1}=w_{t} .
$$

Equation (17) yields the firm's demand for labor:

12. In case of decreasing returns, we implicitly assume - as is standard - that there is some fixed factor in the background (owned by households), which makes the technology (inclusive of this fixed factor) constant returns to scale. 


$$
l_{t}^{d}=\left(\frac{w_{t}}{\eta}\right)^{1 /(\eta-1)},
$$

which shows that, for $0<\eta<1$, labor demand by firms is decreasing in the real wage.

One should note that in the case of a linear production function (i.e., $\eta=$ 1), the first-order condition for profit maximization (eq. [17]) reduces to

$$
w_{t}=1 \text {. }
$$

The labor demand schedule in this case is zero for any real wage above 1 and infinitely elastic for $w_{t}=1$.

\section{Sector $x$ Firms}

Sector $x$ is also characterized by perfectly competitive firms that produce $\operatorname{good} x$. Firms in this sector use an imported input $q$ to produce good $x$, according to the technology given by

$$
x_{t}=q_{t}^{\theta}, \quad \theta \in(0,1),
$$

where $q$ denotes the imported input. The world relative price of $q$ in terms of good $y$ is $p_{q}$, which is assumed to be constant. To economize on notation and with no loss of generality, we assume $p_{q}=1$. Sector- $x$ firms are, however, dependent on bank loans for their working capital needs. In particular, we assume that firms face a credit-in-advance constraint to pay for the imported input:

$$
n_{t} \geq \psi q_{t}, \quad \psi>0,
$$

where $n$ denotes loans from commercial banks. This constraint introduces a demand for bank loans, and hence a credit channel, into the model. As is well known, this constraint will hold as an equality along all paths where the cost of loans, $I^{l}$, is positive. (In addition, we will assume that it holds as an equality if $I^{l}=0$.)

Firms may hold foreign bonds, $b^{x}$. Hence, the real financial wealth of the representative firm at time $t$ is given by $a_{t}^{x}=b_{t}^{x}-n_{t}$. Using $i^{l}$ to denote the lending rate charged by banks and letting $I^{l} \equiv i^{l}-i$ denote the lending spread, we can write the flow constraint faced by the firm as

$$
\dot{a}_{t}^{x}=r a_{t}^{x}+p x_{t}-q_{t}-I_{t}^{l} n_{t}-\Omega_{t}^{x} .
$$

Integrating forward equation (21), imposing the standard transversality condition, and using equations (19) and (20) yields

$$
\int_{0}^{\infty} e^{-r t} \Omega_{t}^{x} d t=a_{0}^{x}+\int_{0}^{\infty}\left[p q_{t}^{\theta}-q_{t}\left(1+\psi I_{t}^{l}\right)\right] e^{-r t} d t .
$$

Note that the credit-in-advance constraint introduces an extra cost of inputs to the firm, given by $\psi I^{l}$ (per unit of input). 
The firm chooses a path of $q$ to maximize the present discounted value of dividends, given by the RHS of equation (22), taking as given the paths for $I_{t}^{l}, r$, and the initial stock of financial assets, $a_{0}^{x}$. The first-order condition for profit maximization is given by

$$
p \theta q_{t}^{\theta-1}=1+\psi I_{t}^{l} .
$$

Equation (23) implies that the demand for the imported input is given by

$$
q_{t}=\left(\frac{p \theta}{1+\psi I_{t}^{l}}\right)^{1 /(1-\theta)} .
$$

Hence, the firm's demand for the imported input is decreasing in the lending spread. This captures the credit channel in our model. Finally, the loan demand by sector- $x$ firms can be determined from equation (24) as

$$
n_{t}=\psi\left(\frac{p \theta}{1+\psi I_{t}^{l}}\right)^{1 /(1-\theta)} .
$$

For later reference, it is useful to note $\partial n / \partial I^{l}<0$ and $\partial^{2} n / \partial\left(I^{I}\right)^{2}>0$. Hence, the input demand for $q$ is also a decreasing and convex function of $I^{l}$.

\subsubsection{Banks}

The economy is assumed to have a perfectly competitive banking sector. We formalize the banking sector along the lines of Lahiri and Végh (2000b). The representative bank takes deposits from consumers, lends to sector- $x$ firms $(n)$, and holds domestic government bonds $\left(z^{b}\right) \cdot{ }^{13}$ The bank charges an interest rate of $i^{l}$ to firms and earns $i^{g}$ on government bonds. It also holds required cash reserves, $m$ (high-powered money). The bank pays depositors an interest rate of $i^{d}$. Thus, the balance sheet identity of the bank implies that $m_{t}+n_{t}+z_{t}^{b}=h_{t}{ }^{14}$

Letting $I^{g}=i^{g}-i$ denote the interest rate spread from lending to the government, the flow constraint of the representative bank is

$$
\Omega_{t}^{b}=I_{t}^{l} n_{t}+I_{t}^{d} h_{t}+I_{t}^{g} z_{t}^{b}-i_{t} m_{t} .
$$

Let $\delta(>0)$ denote the reserve-requirement ratio imposed by the central bank. Note that, because required reserves are non-interest bearing, the

13. Commercial bank lending to governments is particularly common in developing countries. Government debt is held not only as a compulsory (and remunerated) reverse requirement but also voluntarily, due to the lack of profitable investment opportunities in crisis-prone countries. This phenomenon was so pervasive in some Latin American countries during the 1980s that Rodriguez (1991) aptly refers to such governments as "borrowers of first resort." For additional evidence, see Druck and Garibaldi (2000).

14. Similar results would go through if we allowed banks to hold foreign bonds in world capital markets as long as banks face a cost of managing domestic assets (along the lines of Edwards and Végh 1997, Burnside, Eichenbaum, and Rebelo 1999, or Agenor and Aizenman 1999). Put differently - and as is well known - some friction needs to exist at the banking level in order for banks to play a nontrivial role in the credit-transmission mechanism. We chose the specification with no foreign borrowing because it is analytically simpler. 
opportunity cost of holding required reserves for banks is the forgone nominal interest rate, $i$. Hence, at an optimum, the bank will not hold any excess reserves. Formally,

$$
m_{t}=\delta h_{t} .
$$

The representative commercial bank's balance sheet identity can thus be written as

$$
(1-\delta) h_{t}=n_{t}+z_{t}^{b} .
$$

The bank maximizes profits by choosing sequences of $n_{t}, z_{t}^{b}, h_{t}$, and $m_{t}$ subject to equations (27) and (28), taking as given the paths of $I^{l}, I^{d}, I^{g}, \delta$, and $i$. The first-order conditions for the banks' optimization problem are (assuming an interior solution)

$$
\begin{aligned}
& (1-\delta) I_{t}^{l}+I_{t}^{d}=\delta i_{t}, \\
& (1-\delta) I_{t}^{g}+I_{t}^{d}=\delta i_{t} .
\end{aligned}
$$

Conditions (29) and (30) simply say that, at an optimum, the representative bank equates the marginal cost of deposits (RHS) to the marginal revenue from an extra unit of deposits (left-hand side). Note that the marginal revenue from an additional unit of deposits has two components. The first, given by $I_{t}^{d}$, is due to the fact that borrowing from consumers is cheaper for banks (whenever $I_{t}^{d}>0$ ) than borrowing in the open market. The second, given by either $(1-\delta) I_{t}^{l}$ or $(1-\delta) I_{t}^{g}$, captures the fact that banks can lend a fraction $1-\delta$ of each additional unit of deposits to either firms or the government.

Equations (29) and (30) imply that we must have

$$
I_{t}^{g}=I_{t}^{l} .
$$

This also implies that $i^{l}=i^{g}$ : that is, the lending rate to firms must equal the interest rate on government bonds. Intuitively, loans and government bonds are perfect substitutes in the bank's asset portfolio. Because the bank can get $i^{g}$ by lending to the government, it must receive at least as much from firms in order to extend loans to them.

From equation (30), it is also easy to see that the deposit spread, $I^{d}$, is given by

$$
I_{t}^{d}=i_{t}-(1-\delta) i_{t}^{g} .
$$

Because $I^{d}=i-i^{d}$, it follows immediately that we must have $i_{t}^{d}=(1-\delta) i_{t}^{g}$ for all $t$. Thus, a rise in the domestic interest rate, $i^{g}$, must result in a higher deposit rate for consumers and, hence, an increase in demand deposits. Because $i^{g}$ may be controlled by policy makers, the preceding shows that interest rate policy in this model effectively amounts to the government being able to pay interest on money.

Finally, we will restrict attention to parameter ranges for which $I^{d}$ and $I^{l}$ 
are nonnegative. Thus, we will confine attention to environments where $i^{d} \leq$ $i \leq i^{g}$. This restriction is needed to ensure a determinate demand for both loans and demand deposits. Note that this amounts to restricting the relevant interest rates to the range $0 \leq i^{g}-i \leq \delta i^{g}$.

\subsubsection{Government}

The government is composed of the fiscal authority and the monetary authority (i.e., the central bank). The fiscal authority makes lump-sum transfers $(\tau)$ to the public and issues domestic bonds $(Z)$, which are held either by the monetary authority or commercial banks. Domestic bonds are interest bearing and pay $i^{g}$ per unit. The monetary authority issues high-powered money $(M)$, holds government bonds $\left(Z^{g}\right)$, and sets the reserve requirement ratio $(\delta)$ on deposits. The central bank also holds foreign exchange reserves $(R)$, which bear the world rate of interest, $r$. Thus, the consolidated government's flow budget constraint is given by

$$
\dot{R}_{t}=r R_{t}+\dot{m}_{t}+\dot{z}_{t}^{b}+\varepsilon_{t} m_{t}+\left(\varepsilon_{t}-i_{t}^{g}\right) z_{t}^{b}-\tau_{t},
$$

where we have used the fact that the government's net liability to the private sector (in terms of domestic bonds) is $z^{b}=z-z^{g}$ (where $z$ denotes the real stock of domestic bonds and $z^{g}$ is the real stock of domestic bonds held by the central bank).

The central bank's balance sheet identity (in terms of foreign currency) is given by

$$
R_{t}+z_{t}-z_{t}^{b}=m_{t} .
$$

Note that $z^{g}\left(=z-z^{b}\right)$ is the monetary authority's real domestic credit to the public sector. We assume that the fiscal authority keeps the nominal stock of outstanding government debt fixed at $\bar{Z} \cdot{ }^{15}$ Hence,

$$
\frac{\dot{Z}_{t}}{Z_{t}} \equiv \mu_{t}=0, \quad Z_{0}=\bar{Z}
$$

Using equations (34) and (35), equation (33) can be rewritten as:

$$
\tau_{t}=r R_{t}+\varepsilon_{t}\left(m_{t}-z_{t}\right)+\left(\varepsilon_{t}-i_{t}^{g}\right) z_{t}^{b} .
$$

In this model, policy makers may choose to use $i^{g}$ as a policy instrument. In that case, and for analytical convenience, we will think of $I^{g}$ as the policy instrument (recall that, by definition, $I^{g}=i^{g}-i$ ). Given that, as shown below, $i_{t}=r$ for all $t$, the central bank can always set an $i^{g}$ to implement the desired value of $I^{g} .{ }^{16}$ We shall also assume that the government lets fiscal transfers $\tau$ adjust endogenously so that equation (36) is satisfied.

15. This is the natural assumption to make, given that we will abstract from fiscal considerations and focus only on stationary equilibria involving constant nominal variables.

16. For expositional purposes, we will often refer to $I^{g}$ as the domestic interest rate. 
It is useful at this stage to restate the two key effects of interest rate policy in the model. First, because government bonds and bank credit to firms are perfect substitutes in the banks' portfolios, a higher interest rate on government bonds leads to an increase in the lending rate. This reduces bank credit and causes an output contraction (see eq. [24] and [31]). This effect will be referred to as the output effect of interest rate policy. Second, the higher interest rate on government bonds induces banks to also pay a higher rate on bank deposits (recall that $i^{d}=(1-\delta) i^{g}$ ) and, as a result, increases the demand for bank deposits. We will refer to this as the money demand effect.

\subsubsection{Resource Constraint}

By combining the flow constraints for the consumer, the firms in sector $x$ and sector $y$, the bank and the government (eq. [3], [15], [21], [26], and [33]) we get the economy's flow resource constraint:

$$
\dot{k}_{t}=r k_{t}+y_{t}+p x_{t}-c_{t}^{y}-p c_{t}^{x}-q_{t}-v\left(B h_{t} ; \alpha\right),
$$

where $k=R+b+b^{y}+b^{x}$. Note that the RHS of equation (37) is simply the economy's current account. Integrating forward subject to the noPonzi-game condition gives

$$
k_{0}+\int_{0}^{\infty}\left[y_{t}+p x_{t}-c_{t}^{y}-p c_{t}^{x}-q_{t}-v\left(B h_{t} ; \alpha\right)\right] e^{-r t} d t=0 .
$$

\subsubsection{Policy Regimes}

Before proceeding to define the different policy regimes in this economy, notice that the rate of devaluation or depreciation $(\varepsilon)$ will always be zero in this stationary economy. Under a fixed exchange rate, this is trivially true. Under a floating regime, this follows from the fact that (as shown below), the real stock of domestic bonds will be constant along a perfect foresight equilibrium path.

In this economy, policy makers have, in principle, four different policy instruments: the exchange rate $(E)$, international reserves $(R)$, the domestic interest rate $\left(I^{g}\right)$, and nominal domestic credit $\left(Z^{g}\right)$. Only two of these four instruments, however, can be chosen independently. For any two instruments controlled by the central bank, the other two will adjust endogenously. To see this, consider the following equations, which are the relevant ones for monetary policy purposes:

$$
\begin{gathered}
R+\frac{Z^{g}}{E}=\delta h, \\
\bar{Z}=E z^{b}+Z^{g}, \\
n+z^{b}=(1-\delta) h,
\end{gathered}
$$


where $n$ is a function of $I^{g}$ through the loan demand equation (25) (recall that $\left.I^{g}=I^{l}\right), h$ is a function of $I^{d}$ through the money demand equation (13), and $I^{g}$ and $I^{d}$ are linked through equation (30) (recall that, as will be shown below, $\varepsilon=0$ ). Equation (39) is the central bank's balance sheet, equation (40) is the equilibrium condition in the government bond market, and equation (41) is the commercial bank's balance sheet. Equations (39)-(41) thus define a system of three equations in five unknowns $\left(E, R, z^{b}, Z^{g}\right.$, and $\left.I^{g}\right)$. This implies that there are two policy variables that can be set by policy makers.

For the purposes of the subsequent analysis, we can therefore define the following policy regimes:

1. Fixed exchange rate. Policy makers fix $E$ at a certain level and set $Z^{g}$. Both international reserves and $I^{g}$ adjust endogenously. ${ }^{17}$ This regime is intended to capture a hard peg (in the style of Argentina or Hong Kong) in which the monetary authority maintains a constant backing (in terms of international reserves) of the monetary base and thus completely forgoes active monetary policy (i.e., the monetary authority allows $I^{g}$ to be determined by market forces).

2. Pure floating. Policy makers fix $R$ at a certain level and set $I^{g}$. Both the exchange rate and $Z^{g}$ adjust endogenously. This regime is intended to capture a floating regime in which policy makers actively engage in monetary policy by setting domestic interest rates.

3. Dirty floating. Policy makers set $R$ (and may change it in response to shocks) as well as $I^{g}$, whereas $E$ and $Z^{g}$ adjust endogenously.

4. Fully sterilized intervention. Policy makers target a constant level of $h$ (real demand deposits) - and hence of the real monetary base - and set the level of $z^{g}$ (real domestic credit). In this case, both reserves and the exchange rate adjust endogenously.

\subsubsection{Flexible Wages Equilibrium}

We now characterize the perfect foresight equilibrium path (PFEP) for this economy under flexible wages and floating exchange rates (either the pure floating or the dirty floating regimes, as defined above) under the assumption that $\alpha$ is expected to remain constant over time. In both cases (pure and dirty floating), policy makers keep the stock of international reserves constant along a PFEP. ${ }^{18}$ Along this PFEP, policy makers set $i^{g}$ at a

17. We will also refer to this case below as the full intervention case, because the central bank keeps the exchange rate fixed by intervening in the foreign exchange market.

18. Under dirty floating, and in response to unanticipated shocks to money demand (as analyzed below), the central bank will be allowed to undertake a discrete intervention when the shock hits. Notice that if the path of $\alpha$ were not constant over time (a case we do not address here), dirty floating could also be characterized by discrete interventions along a PFEP. 
constant level. Because, as shown above, $i^{d}=(1-\delta) i^{g}$, this implies that $i^{d}$ is also constant along a PFEP.

The labor market clearing condition dictates that labor demand equal labor supply, that is, $l_{t}^{s}=l_{t}^{d}$. Imposing this condition on equations (12), (17), and (25) yields the equilibrium labor and real wage for this economy (equilibrium values of labor and real wage are denoted with a bar):

$$
\begin{aligned}
\bar{l} & \equiv\left(\frac{B \eta}{\zeta v}\right)^{1 /(\nu-\eta)}, \\
\bar{w} & =\eta\left(\frac{B \eta}{\zeta v}\right)^{(\eta-1) /(v-\eta)} .
\end{aligned}
$$

In other words, along a PFEP, both employment and the real wage are constant.

Next, notice that the evolution of the stock of real domestic bonds is given by $\dot{z} / z=-\varepsilon$ (because, by definition, $z=Z / E$ and $Z$ is constant from eq. [35]). By combining equations (39) and (41), we obtain $z=h-n-R_{0}$. Recall from equations (13) and (25) that $h$ is a decreasing function of $r+$ $\varepsilon-i^{d}$, whereas $n$ is a decreasing function of $i^{g}-r-\varepsilon$. Because $i^{g}$ and $i^{d}$ are constant along a PFEP, it follows that $z$ is solely a function of $\varepsilon$ along such a path. Furthermore, we can implicitly solve for $\varepsilon$ as a function of $z$ and write $\varepsilon=\widetilde{\varepsilon}(z)$, where, as can be easily verified, $\widetilde{\varepsilon}^{\prime}(z)<0$. Hence, it follows that

$$
\dot{z}_{t}=-\widetilde{\varepsilon}\left(z_{t}\right) z_{t} .
$$

By linearizing equation (44) around a steady state (where $\widetilde{\varepsilon}\left[z_{t}\right]=0$ ), it follows that this is an unstable differential equation. Hence, $z$ must always be equal to its steady-state level. This implies, in turn, that $\varepsilon=0$ along a PFEP. Hence, $h$ and $n$ are also constant along a PFEP. This determines, through equation (41), the level of $z^{b}$. For this level of $z^{b}$ and a given $R_{0}$, equations (39) and (40) determine the constant level of the exchange rate:

$$
\bar{E}=\frac{\bar{Z}}{\bar{m}-R_{0}+\bar{z}^{b}},
$$

where $\bar{m}(=\delta \bar{h})$ and $\bar{z}^{b}$ denote the constant values of real money balances and loans. Equation (45) shows that policy makers have two avenues for influencing the exchange rate. First, for a given $R_{0}$, they can use interest rate policy to affect $I^{d}$ and $I^{l}$. This will influence $\bar{m}$ and $\bar{z}^{b}$ directly and, hence, change $E$. Second, for a given $\bar{m}$ and $\bar{z}^{b}$, they can intervene in the foreign exchange market and alter the level of $R_{0}$ and, hence, $E$. The determination of the optimal mix of these two policies is an issue that we will return to later.

In order to determine steady-state consumption, notice that equation (11) implies that the ratio $c^{x} / c^{y}$ is a constant. Hence, $c / c^{y}$ must also be constant. This, combined with the first-order condition for consumption and the fact that the equilibrium level of employment $\bar{l}$ is constant, implies that 
$c^{y}, c^{x}$, and $c$ must all be constant. The country resource constraint then implies that the constant levels of consumption of the two goods are given by

$$
\begin{aligned}
& \bar{c}^{y}=\rho\left[r k_{0}+\bar{l}^{\eta}+p\left(\frac{p \theta}{1+\psi I^{l}}\right)^{\theta /(1-\theta)}-\left(\frac{p \theta}{1+\psi I^{I}}\right)^{1 /(1-\theta)}-v\left(B h_{t} ; \alpha\right)\right], \\
& p \bar{c}^{x}=(1-\rho)\left[r k_{0}+\bar{l}^{\eta}+p\left(\frac{p \theta}{1+\psi I^{l}}\right)^{\theta /(1-\theta)}-\left(\frac{p \theta}{1+\psi I^{l}}\right)^{1 /(1-\theta)}-v\left(B h_{t} ; \alpha\right)\right] .
\end{aligned}
$$

\subsubsection{Money Demand Shocks under Flexible Wages}

As a benchmark case, consider an unanticipated and permanent fall in $\alpha$ (i.e., a negative money demand shock) under a pure floating rate and flexible wages. Because real money demand decreases, the nominal exchange rate rises instantaneously (i.e., the currency depreciates) to accommodate the lower real money demand (see eq. [45]). Furthermore, the nominal wage rises by the same proportion as the exchange rate. Thus, with an unchanged interest rate policy, the real side of the economy remains completely insulated. Consumption of both goods falls because the equilibrium level of transactions cost rises. Note that under a fixed exchange rate (i.e., full intervention), the economy would also adjust instantaneously as the central bank intervenes in the foreign exchange market (by selling international reserves), thus accommodating the fall in real money demand.

\subsection{Nominal Wage Rigidities}

\subsubsection{Perfect Foresight Equilibrium Path under Flexible Exchange Rates}

We now depart from the flexible wages paradigm by introducing a nominal wage rigidity into the model. We will examine first the case of flexible exchange rates. ${ }^{19}$ We assume that nominal wages cannot jump at any point in time. Hence, the labor market clearing condition $l^{d}=l^{s}=\bar{l}$ does not necessarily hold at all points in time. In particular, it is assumed that nominal wages, $W$, adjust according to the following dynamic equation:

$$
\dot{W}_{t}=\gamma\left(\bar{w}-\frac{W_{t}}{E_{t}}\right), \quad W_{0} \text { given, }
$$

where $\gamma \in(0, \infty)$ captures the speed of adjustment toward the equilibrium real wage, $\bar{w}$. Recall that $\bar{w}$ is given by equation (43). The implication of introducing sticky nominal wages (as shown below) is that a depreciation of the currency will now lead to a fall in the real wage and cause a temporary labor market disequilibrium and concomitant output losses in sector $y$.

19. As will become clear below, in the fixed exchange rate case, the real sector remains insulated from monetary shocks. 
Using the previously shown result that, along any PFEP with flexible exchange rates, $E$ must already be at its steady state value $\bar{E}$ at time $t=0$, one can solve equation (46) to get

$$
w_{t}=\bar{w}+e^{-(\gamma / \bar{E}) t}\left(w_{0}-\bar{w}\right),
$$

where $w_{t}=W_{t} / \bar{E}$ and $w_{0}=W_{0} / \bar{E}$. Notice that $\lim _{t \rightarrow \infty} w_{t}=\bar{w}$. Moreover, $\dot{w}_{t} \gtreqless 0$ for $w_{t} \lesseqgtr \bar{w}$. Finally, the equilibrium nominal wage is given by $\bar{W}=\bar{w} \bar{E}$.

As in standard disequilibrium models, it will be assumed that actual employment is given by the short end of the market. In other words, when the real wage is below (above) its equilibrium value, actual labor is determined by labor supply (demand). Notice that this disequilibrium model implies that only one of the two labor optimality conditions will hold. If the real wage is below its equilibrium value, the household's labor condition (eq. [9]) will hold, but the firm's (eq. [18]) will not. Conversely, if the real wage is above its equilibrium value, the firm's first order condition will hold, but the household's will not.

There are two potential cases of disequilibrium. For $w_{0}<w_{t}<\bar{w}$, we have $l_{t}^{a}=l_{t}^{s}=\left(B w_{t} / \nu \zeta\right)^{1 /(v-1)}$. Substituting in for $w_{t}$ from equation (47) and simplifying the result yields the path for actual employment:

$$
l_{t}^{a}=\bar{l}\left[1+\left(\frac{w_{0}}{\bar{w}}-1\right) e^{-(\gamma / \bar{E}) t}\right]^{1 /(v-1)},
$$

with $l_{0}^{a}=\left(B w_{0} / \nu \zeta\right)^{1 /(v-1)}$. Analogously, for the case $w_{0}>w_{t}>\bar{w}$, we have $l_{t}^{a}=$ $l_{t}^{d}=\left(w_{t} / \eta\right)^{1 /(\eta-1)}$. The path for actual employment is now given by

$$
l_{t}^{a}=\bar{l}\left[1+\left(\frac{w_{0}}{\bar{w}}-1\right) e^{-(\gamma / \bar{E}) t}\right]^{-1 /(1-\eta)},
$$

with $l_{0}^{a}=\left(w_{0} / \eta\right)^{1 /(\eta-1)}$. Substituting these relations into equation (14) yields the time path of output of good $y$ for each case.

It is useful to note that, in both cases, $l^{a}<\bar{l}$ throughout the transition. Intuitively, any deviation of the real wage from its equilibrium value implies that the short end of the labor market determines actual employment. In the case of an unanticipated increase in the real wage, labor demand falls while labor supply goes up (relative to the equilibrium). Because labor demand is the short side of the market, actual employment equals labor demand. Hence, output of sector $y$ falls. Conversely, when the real wage is below the equilibrium, labor supply is smaller, whereas labor demand is greater relative to the equilibrium. In this event, actual employment is supplydetermined. Hence, employment falls and output of sector $y$ declines. ${ }^{20}$

This result is key to understanding the real effects of exchange rate fluctuations within this model. It implies that currency appreciation and depreciation are both contractionary. This result stands in stark contrast to

20. This case is exactly what Barro and Grossman (1971) called "voluntary unemployment" in their analysis of disequilibrium models. 
Table 14.2

Response to a Negative Money Demand Shock

\begin{tabular}{|c|c|c|c|c|c|}
\hline Policy Regime & $R$ & $E$ & $I^{g}$ & $z^{g}$ & $h$ \\
\hline Fixed exchange rate & $\downarrow$ & $\rightarrow$ & $\uparrow$ & $\rightarrow$ & $\downarrow$ \\
\hline Floating exchange rate & $\rightarrow$ & $\uparrow$ & $\rightarrow$ & $\downarrow$ & $\downarrow$ \\
\hline Dirty floating & $\downarrow$ & $\uparrow$ & $\rightarrow$ & $\rightarrow$ & $\downarrow$ \\
\hline Full sterilization & $\downarrow$ & $\downarrow$ & $\uparrow$ & $\uparrow$ & $\rightarrow$ \\
\hline Optimal policy (small shock) & $\rightarrow$ & $\uparrow$ & $\uparrow$ & $\downarrow$ & $\downarrow$ \\
\hline Optimal policy (large shock) & $\downarrow$ & $\rightarrow$ & $\rightarrow$ & $\uparrow$ & $\downarrow$ \\
\hline
\end{tabular}

Note: Under dirty floating, the increase in $E$ is smaller than under pure floating.

the standard Mundell-Fleming model with rigid prices in which depreciations are expansionary whereas appreciations are contractionary. The difference arises because the standard models in the Mundell-Fleming tradition postulate output to be demand-determined, with demand being a function of the real exchange rate. As this model shows, introduction of an explicit supply side alters the implications quite dramatically.

The consumption dynamics along the adjustment path can be determined directly from the employment dynamics. Noting that $\lambda$ is constant along a PFEP and $c^{x} / c^{y}$ and $c / c^{y}$ are both constants at all times, one can differentiate the first-order condition (eq. [7]) with respect to time to get

$$
\dot{c}_{t}=\zeta \nu\left(l_{t}^{a}\right)^{\nu-1} \dot{l}_{t}^{a}>0
$$

which says that consumption rises along with employment during the transition. There is a unique time path of consumption that satisfies equation (50) and the intertemporal resource constraint. Given the paths for $c$ and $l^{a}$, the values of $c_{0}$ and $l_{0}^{a}$ would then determine the value of the multiplier through the first-order condition given by equation (7). Clearly, welfare will be lower than it would be under flexible wages (and floating rates), because either firms in sector $y$ are forced to accept a path for labor that does not satisfy their first-order condition given by equation (17), or the first-order condition for households, equation (9), is violated. ${ }^{21}$

\subsubsection{The Menu of Policy Options}

We can now describe the economy's response to a negative money demand shock (i.e., an unanticipated and permanent fall in $\alpha$ ) in the presence of sticky wages under the four policy regimes defined above. (Table 14.2 summarizes the outcome under these four different options.) Notice that, on the monetary side, the economy will always adjust instantaneously to this shock. On the real side, sector- $x$ output will always adjust instantaneously as well. On the other hand, sector- $y$ output will adjust gradually over time if the exchange rate deviates from its initial steady state along the lines described above.

21. Notice that an important advantage of this framework over a model with demanddetermined output is that welfare analysis in our model is well defined. 
1. Fixed exchange rate. Under a fixed exchange rate, policy makers respond to the shock by keeping $E$ and $Z^{g}$ unchanged. Hence, real domestic credit, $z^{g}$, also remains unchanged. From equation (40), it follows that $z^{b}$ will not change either. Because the negative money demand shock reduces real demand for deposits, the commercial bank's balance sheet (eq. [41]) implies that loans, $n$, must fall. However, this can only occur through a rise in $I^{g}$. In the new equilibrium, the fall in real money demand is smaller than the initial shock because the rise in the domestic interest rate partially offsets the money demand shock. International reserves decline endogenously to accommodate the lower level of base money.

Intuitively, the initial fall in real demand deposits induces a fall in the demand for government bonds by commercial banks. At unchanged levels of central bank holdings of government bonds, $z^{g}$, and the nominal exchange rate, $E$, this implies an excess supply of government bonds. The central bank responds to this by raising domestic interest rates, because this makes domestic bonds and demand deposits more attractive to the private sector.

On the real side, sector- $y$ output remains unchanged at its equilibrium level. Since the exchange rate is fixed, the actual wage will not deviate from the equilibrium real wage, and there will be no disequilibrium in the labor market. In contrast, higher domestic interest rates extract an output cost in sector $x$ as banking credit becomes more expensive and banking lending falls. In addition, the fall in real money balances implies an increase in transaction costs.

2. Pure floating. Under pure floating, policy makers respond to the negative money demand shock by keeping international reserves, $R$, and the domestic interest rate, $I^{g}$, unchanged, while allowing the exchange rate and domestic credit to adjust endogenously. An unchanged domestic interest rate implies that base money falls by the full amount of the shock. Because $R$ is unchanged, real domestic credit, $z^{g}$, must fall to accommodate the shock. The fall in demand deposits along with an unchanged lending rate (and hence loan demand) implies that the demand for government bonds by commercial banks, $z^{b}$, falls. The excess supply of government bonds implies that its price, $1 / E$, falls: that is, the currency depreciates.

In the pure floating case, sector $x$ remains completely insulated from the shock, because the domestic interest rate remains unchanged. However, the depreciation of the currency implies a fall in the real wage. Hence, the labor market goes into disequilibrium on impact and returns to the steady state asymptotically, as shown by equations (47) and (48). Hence, the output of sector $y$ remains below the steady-state level throughout the adjustment period. Moreover, the policy also implies a contraction in real deposits and, hence, higher transaction costs and lower consumption.

3. Dirty floating. Under dirty floating, policy makers intervene in the foreign exchange market (by selling international reserves) to achieve a smaller increase in the exchange rate (i.e., a smaller depreciation) than under the pure floating case. Specifically, suppose that policy makers reduce $R$ so as to main- 
tain the stock of real domestic credit unchanged. Then, because $I^{g}$ does not change, it follows from equation (41) that $z^{b}$ will fall. This, in turn, implies from equation (40) that $E$ rises. Notice that this rise in $E$ will be less than in the pure floating case described above. The reason is that $z^{b}$ falls by the same amount in either case, whereas $z^{g}$ falls under a pure float but does not change under dirty floating. From equation (40), it follows that $E$ will rise by less.

Intuitively, starting from the pure floating case described above, policy makers intervene in foreign exchange markets by selling international reserves. Because the domestic interest rate is kept unchanged, the lower stock of international reserves will be reflected in a higher stock of real domestic credit. This implies that, at the level of the exchange rate that prevails under pure floating, there is an excess demand for government bonds. Hence, their price $(1 / E)$ must increase, which implies that $E$ must fall (relative to the pure floating case). The outcome is that the currency depreciates by less than it does in the pure floating case, while international reserves fall.

Because the currency depreciates by less under dirty floating, the output losses in sector $y$ will be lower than under pure floating. There are no output costs in sector $x$.

4. Fully sterilized intervention. In our definition, the case of a fully sterilized intervention means keeping the level of real money demand unchanged and targeting a higher level of real domestic credit. ${ }^{22}$ In this case, the domestic interest rate, the level of international reserves, and the exchange rate will adjust endogenously. In order for real demand deposits to remain unchanged, equation (13) implies that $(\alpha / 2)-\left(I^{d} / 2 B\right)$ must remain unchanged. Hence, in response to a fall in $\alpha, I^{d}$ must fall. From equation (30), a fall in $I^{d}$ implies a rise in $I^{g}$. Hence, loans $(n)$ must fall, while commercial bank holdings of government debt $\left(z^{b}\right)$ rise by an offsetting amount. Because, by construction, $z^{g}$ has gone up, the nominal exchange rate must fall (i.e., the currency appreciates). International reserves fall one-to-one with the increase in real domestic credit.

Intuitively, under a fully sterilized intervention, the central bank reacts to a negative money demand shock by increasing domestic credit through a purchase of government bonds while raising the domestic interest rate in order to keep money demand unchanged. The resulting increase in the lending rate causes sector- $x$ firms to reduce their loan demand. Commercial banks react to the lower demand for loans by increasing their demand for government bonds. Hence, the total demand for government bonds rises. Because the nominal supply of these bonds is fixed, their price, $1 / E$, must rise. Hence, $E$ must fall (i.e., the currency appreciates). The final outcome is a change in the composition of central bank assets (lower international reserves and higher real domestic credit) with no change in the level.

22. Naturally, this scenario assumes that the initial level of $\hat{h}$ is still technologically feasible after the shock. (Recall from eq. [6] that the transaction technology imposes the restriction that $\hat{h} \leq \alpha / 2$.) 
While this policy succeeds in insulating domestic money demand from the negative shock (which implies that transaction costs fall by less than they would otherwise), this insulation comes at the expense of higher domestic interest rates and an appreciation of the currency. The higher interest rate causes an output contraction in sector $x$. The appreciation, on the other hand, induces a rise in the real wage (recall that nominal wages are rigid) and a fall in labor demand and sector- $y$ output.

In the next section we will show that the optimal policy mix (when intervention is costless) implies that none of these extreme cases is optimal. Instead, the optimum falls somewhere in the "interior" of these pure cases.

\subsubsection{Real versus Monetary Shocks}

We conclude this section by noting that this model reproduces the standard Mundell-Fleming results regarding the optimal exchange rate regime under fixed and flexible rates. Under fixed exchange rates, sticky wages make no difference in the adjustment path of the economy. Put differently, the economy adjusts instantaneously under fixed rates and sticky wages, as the central bank buys and sells reserves to keep $E$ unchanged. Thus, relative to flexible exchange rates, fixed exchange rates are better for insulating the real side of the economy from monetary shocks.

To think about real shocks in this model, consider a shock to $p$, the relative price of good $x$. This shock changes the equilibrium real wage and, hence, requires a change in the market real wage. Under flexible rates, this would happen instantaneously through a change in the nominal exchange rate. Under fixed exchange rates and rigid nominal wages, the economy cannot adjust instantaneously, because neither the nominal wage nor the nominal exchange rate can jump. The economy returns to the long-run equilibrium only through a slow adjustment of the nominal wage accompanied by an output contraction in sector $y$ (unless, of course, there is a policy change in the exchange rate). Thus, for the purposes of insulating the real side of the economy from real shocks, flexible exchange rates are better than fixed exchange rates.

\subsection{Optimal Stabilization Policy}

Having described the adjustment of the economy to money demand shocks under different policy regimes, we now turn to the issue of the optimal policy response to such shocks. ${ }^{23}$ For the purposes of solving for the optimal policy response to a monetary shock, we will view policy makers as optimally choosing the domestic interest rate, $I^{g}$, and the level of international reserves (which, if different from the preshock level, implies a discrete

23. For analytical convenience, this section solves for the optimal policy in the absence of a fixed cost of intervention (a key feature of the model to be introduced in the next section). The next section solves for the optimal policy problem in the complete model. 
one-shot intervention in the foreign exchange market). It is clear from equations (39)-(41) that an optimal choice of $I^{g}$ and $R$ will imply a unique choice of $E, Z^{g}$, and $z^{b}$.

To study the optimal policy response, start from a steady state with $\alpha=$ $1, E=\bar{E}, m=\bar{m}$, and $R=\bar{R}$, and consider an unanticipated and permanent fall in $\alpha$ at time $t=0$. The policy maker's goal is to choose $I_{0}^{g}$ and $R_{0}$ to maximize the welfare of the representative agent. Solving the optimal policy problem becomes greatly simplified due to the following proposition.

PROPOSITION 1. Given any choice of $I_{0}^{g}$ by the policy maker in response to a money demand shock (i.e., an $\alpha$ shock), it can never be optimal for the central bank to choose an $R_{0}$ such that $E_{0} \neq \bar{E}$.

Proof. Recall that any $E_{0} \neq \bar{E}$ implies that the market real wage $W_{0} / E_{0} \neq$ $\bar{w}=W_{0} / \bar{E}$, where $\bar{w}$ is the equilibrium real wage. Hence, output and employment must fall on impact and then rise gradually back toward the longrun steady state. The central bank can always choose $R_{0}$ such that $\bar{m}-\bar{R}+$ $\bar{z}^{b}=m_{0}-R_{0}+z_{0}^{b}$. Such a choice of $R_{0}$ would imply that $E_{0}=\bar{E}$, which would leave the labor market completely unaffected and, hence, the output of sector $y$ unchanged. Moreover, output of sector $x$ is independent of the size of the intervention. Because intervention is costless from the perspective of the country as a whole, country wealth is unaffected by the size of intervention (a larger $R$ merely corresponds to lower private foreign bond holdings, $b$, leaving $k$ unchanged). Hence, this particular choice of $R_{0}$ dominates any other postshock choice of reserves.

Proposition 1 implies that the policy maker will respond to a monetary shock by always keeping the nominal exchange rate unchanged so as to insulate the economy from any labor market frictions. Hence, at the time of the shock, the economy adjusts immediately to a new stationary equilibrium. The problem is thus reduced to a choice of optimal real money balances in a stationary economy through an appropriate choice of $I^{g}$. Once $m$ (and hence $z^{b}$ ) is chosen, the optimal intervention involves choosing an $R_{0}$ such that $E_{0}=\bar{E}$.

Note that proposition 1 immediately eliminates from the set of optimal policies the option of allowing the adjustment (in part or in its entirety) to occur through an adjustment of the nominal exchange rate. Hence, it is already clear that neither the pure floating nor the dirty floating regimes considered above will prove to be the optimal policy response.

The stationarity of the economy implies that the representative household's lifetime welfare is given by

$$
W=\frac{1}{r\left(1-\frac{1}{\sigma}\right)}\left[\left(c-\zeta \bar{l}^{\nu}\right)^{1-(1 / \sigma)}-1\right],
$$


which takes into account the fact that the policy maker will ensure that the labor market is always in equilibrium. Hence, $l^{a}=\bar{l}$. For a stationary economy, the country resource constraint given by equation (38) implies that

$$
c^{y}+p c^{x}=r k_{0}+\bar{l}^{\eta}+p q^{\theta}-q-\left(\hat{h}^{2}-\alpha \hat{h}+\kappa\right) .
$$

Moreover, the first-order conditions for consumption imply that $c^{y}+p c^{x}=$ $c^{y} / \rho$ and $c / B=c^{y} / \rho$. Hence, the economy's resource constraint reduces to

$$
c=B\left[r k_{0}+\bar{l}^{\eta}+p q^{\theta}-q-\left(\hat{h}^{2}-\alpha \hat{h}+\kappa\right)\right] .
$$

Because $c-\zeta \bar{\zeta}^{v}$ is constant along any perfect foresight equilibrium path while $W$ is monotonically rising in $c-\zeta \bar{l}^{v}$, the policy maker's problem reduces to choosing $I^{g}, I^{g} \in\{0,[\delta /(1-\delta)] r\}$, to maximize $c-\zeta \bar{l}^{v}\left(\equiv \hat{W}^{\text {peg }}\right)$ subject to equations (13), (24), and (30), for a given $\alpha, k_{0}$, and $\bar{l}$. Note that welfare in this case corresponds to welfare under a fixed exchange rate.

The country resource constraint implies that

$$
\hat{W}^{p e g}=B r k_{0}+B \bar{l}^{\eta}-\zeta \bar{l}^{\nu}+B\left(p q^{\theta}-q\right)-B\left(\hat{h}^{2}-\alpha \hat{h}+\kappa\right) .
$$

Differentiating $\hat{W}^{\text {peg }}$ with respect to $I^{g}$ gives

$$
\frac{d \hat{W}^{p e g}}{d I^{g}} \equiv \Gamma=-\frac{B \psi^{2}(p \theta)^{1 /(1-\theta)} I^{g}}{(1-\theta)}\left(\frac{1}{1+\psi I^{g}}\right)^{(2-\theta) /(1-\theta)}+\frac{(1-\delta)}{2 B} I^{d} .
$$

In the following we shall use $I_{\text {peg }}^{g}$ to denote the optimal value of $I^{g}$ in the case where the policy maker keeps the exchange rate pegged at all times. $I_{p e g}^{g}$ is defined by the relation $\left.\Gamma\right|_{I_{\text {sec }}}=0$. It is easy to determine from equation (52) that $\left.\Gamma\right|_{I^{s=0}}>0$ and $\left.\Gamma\right|_{I^{s}=[\delta /(1-\delta)] r} ^{I_{p^{*}}}<0$. Hence, $I_{p e g}^{g} \in\{0,[\delta /(1-\delta)] r\}$. In other words, the optimal domestic interest rate lies strictly in the interior of the permissible range. Note that $I^{g}=[\delta /(1-\delta)] r$ corresponds to $I^{d}=0$, which is equivalent to implementing the Friedman rule.

Equation (52) clearly shows the two key margins over which the policy maker chooses the optimal $I^{g}$. First, a higher $I^{g}$ implies that $I^{l}$ goes up. Hence, the cost of funds for sector- $x$ firms goes up, which implies that output (net of the import bill) and, consequently, consumption falls. This effect is captured by the first term on the RHS of equation (52). However, a higher $I^{g}$ also implies a higher deposit rate for depositors and hence a lower opportunity cost of holding deposits, $I^{d}$. This causes money demand to go up, which, in turn, reduces transaction costs and thereby increases consumption. This is the positive money demand effect of higher domestic interest rates that is captured by the second term in the RHS of equation (52). Note that the Friedman rule $\left(I^{d}=0\right)$ emerges as the optimum when $\psi=0$. When $\psi=0$, higher lending rates do not have any output effect, because firms do not rely on bank credit at all. Thus, it is optimal to raise the domestic interest rate all the way to $I^{g}=[\delta /(1-\delta)] r$, which implies that $I^{d}=0$, thereby achieving the lowest possible level of transaction costs. 
For $I_{p e g}^{g}$ to be an optimum, we must also ensure that the second-order condition for a maximum is satisfied. The condition $\psi r[\delta /(1-\delta)]<1-\theta$ is sufficient (but not necessary) to satisfy the second-order condition for the government's welfare maximization problem. Moreover, this condition implies that $\hat{W}^{\text {peg }}$ is globally concave in $I^{g}$; hence, the optimal solution, $I_{\text {peg }}^{g}$, is unique. We omit a detailed statement of the proof because it follows simply from differentiating $\Gamma$ with respect to $I^{g}$. In what follows we shall restrict attention to parameter ranges for which the second-order condition is satisfied.

Of key interest to us is the behavior of the optimal domestic interest rate as a function of $\alpha$. In particular,

$$
\frac{d I_{p e g}^{g}}{d \alpha}=-\frac{\partial \Gamma / \partial \alpha}{\partial \Gamma / \partial I^{g}}=0
$$

since $\partial \Gamma / \partial I^{g}<0$ (from the second-order condition for welfare maximization) and $\partial \Gamma / \partial \alpha=0$. We state this result in the following proposition.

Proposition 2. The optimal domestic interest rate, $I_{\text {peg }}^{g}$, is independent of the money demand parameter $\alpha$. Hence, a negative money demand shock (a fall in $\alpha$ ) or a positive money demand shock (a rise in $\alpha$ ) leaves $I_{p e g}^{g}$ unchanged.

This proposition says that a social welfare-maximizing policy-maker, who keeps the exchange rate fixed by fully intervening in the foreign exchange market, should not alter the domestic interest rate in response to money demand shocks. Intuitively, at an optimum, the marginal benefit in terms of reducing transaction costs, given by the last term on the RHS of equation (52), is independent of $\alpha$. There is therefore no reason for the optimal domestic interest rate to change. Because $\hat{h}=(\alpha / 2)-\left(I^{d} / 2 B\right)$, a change in $\alpha$ merely induces a corresponding parallel shift up or down in money demand but leaves unchanged the marginal benefit of changing the domestic interest rate. Hence, both $\hat{h}$ and $h$ fall in response to a negative money demand shock.

The preceding analysis allows us to tie down the behavior of all the endogenous variables in the model in response to a money demand shock. We summarize them in the following proposition.

Proposition 3. An unexpected fall (rise) in $\alpha$ causes real money balances to fall (rise). The central bank responds to the shock by intervening in the foreign exchange market by selling (buying) international reserves in order to keep the nominal exchange rate unchanged at the preshock level. The domestic interest rate, $I^{g}$, is kept unchanged. Because neither the domestic interest rate nor the exchange rate changes, output of both sectors remains unaffected. Furthermore, real domestic credit increases (falls) whereas international reserves fall (increase). 
Notice how, in response to a negative money demand shock, the optimal policy response involves elements of the four regimes described above. Specifically, the fall in real money demand is accommodated fully through foreign exchange market intervention (i.e., selling reserves), without any change in the exchange rate, as would happen under a fixed exchange rate. In addition, the domestic interest rate is kept unchanged (i.e., monetary policy is not tightened in response to the shock), as would occur under either a pure or dirty float. Finally, the optimal response also involves an increase in real domestic credit, as would occur if policy makers were attempting to (partially) sterilize the fall in real money demand.

It is worth stressing that the existence of nominal wage rigidities is key in generating the result that the nominal exchange rate should be kept fixed. In the absence of nominal wage rigidities, exchange rate fluctuations are costless. In that event, the central bank has no incentive to intervene, which implies that a pure float is optimal..$^{24,25}$

\subsection{Costly Intervention}

This section completes the specification of the general model by incorporating costly intervention and derives the optimal policy response in such a case. We proceed in two steps. We first study the optimal policy contingent on no intervention and then contingent on intervention; we then confront the question of when it will be optimal for policy makers to intervene.

\subsubsection{Optimal Policy under Intervention}

As before, we analyze the effects of a negative money demand shock. In particular, starting from a steady state with $\alpha=1$, we study the effects of an unanticipated and permanent fall in $\alpha$. To simplify notation, and without loss of generality, we also choose initial conditions such that $\bar{E}=1$ and $\bar{R}=0$. For $\bar{R}=0$, this corresponds to an initial situation in which $\bar{Z}=h-n$. To see this, one can rewrite the central bank balance sheet as $E=\bar{Z} /\left(z^{b}+\right.$ $m-R)$. However, the commercial bank balance sheet implies that $z^{b}=h-$ $m-n$. Hence, for $R=0$, the expression for $E$ reduces to

$$
E=\frac{\bar{Z}}{h-n} \text {. }
$$

24. In the absence of nominal wage rigidities, the policy maker is essentially indifferent between intervening and not intervening, because allocations are independent of the level of the exchange rate. However, even an infinitesimal cost of intervening would imply that the optimal policy is a pure float.

25. We should note that the strict independence of the optimal interest rate from the money demand shock is due to the quadratic transaction costs technology. In a more general setup for transaction costs, say $\alpha v(\hat{h})$, it is easy to show that the optimal response to a negative money demand shock is to raise the domestic interest rate to partially offset the effect of the shock on money demand. Hence, optimal policy, in general, would entail a combination of higher interest rates and foreign exchange market intervention. 
Finally, we also assume that in the initial steady state the domestic interest rate is given by the solution to the optimal policy problem under costless intervention. Hence, $\bar{I}^{g}=I_{p e g}^{g}$, while $n$ and $h$ are given by their corresponding levels under $I_{p e g}^{g}$.

For simplicity, we assume that the central bank incurs a fixed cost $\phi>0$ in the event that it intervenes in the foreign exchange market. Moreover, this fixed cost is symmetric: it applies to either an increase or a decrease in the stock of reserves. ${ }^{26}$ Clearly, if $\phi=0$, the model reduces to the one analyzed earlier in which the optimal response is to fully insulate the exchange rate from all money shocks. Under this general specification, the resource constraint for the economy now becomes

$$
k_{0}-\phi+\int_{0}^{\infty}\left[\left(l_{t}^{a}\right)^{\eta}+p q_{t}^{\theta}-c_{t}^{y}-p c_{t}^{x}-q_{t}-\left(\hat{h}^{2}-\alpha \hat{h}+\kappa\right)\right] e^{-r t} d t=0 .
$$

It is useful to begin by noting that, because the intervention cost is fixed and independent of the size of the intervention, there can only be two potential outcomes to the policy maker's problem. Either the monetary authority pays the fixed cost of intervention and intervenes by the full amount necessary to keep the nominal exchange rate unchanged, or it does not intervene at all. ${ }^{27}$

In the event that the policy maker intervenes, optimal policy will coincide with that under costless intervention (which was derived above). This follows from the fact that the cost of intervention is independent of the size of intervention. Consequently, none of the marginal conditions for optimal policy are affected. The policy maker would thus respond to a negative money demand shock by keeping the domestic interest rate and the nominal exchange rate unchanged. Money demand would therefore fall by the full amount of the shock. Hence, under full intervention, output of both sectors remains completely invariant to changes in $\alpha$.

In this case, the representative household's welfare is increasing in $c-\zeta \bar{l}^{v}$ $\left(\equiv \hat{W}^{I}\right)$, which is given by

$$
\hat{W}^{I}=B r k_{0}+B \bar{l}^{\eta}-\zeta \bar{l}^{v}+B\left(p q^{\theta}-q\right)-B\left(\hat{h}^{2}-\alpha \hat{h}+\kappa\right)-B r \phi,
$$

where we have used the resource constraint (eq. [54]) to substitute out for $c$.

26. We take this fixed cost to be a highly heuristic representation of a world with asset market segmentation in which agents must pay a fixed cost to transfer money between the goods market and the asset market, along the lines of Alvarez, Atkeson, and Kehoe (1999). Formalizing this channel is far from trivial (because the main exercise involves performing comparative statics for the optimal policy) and is left for future research. See also Cadenillas and Zapatero (1999), who derive the optimal intervention policy for the central bank in a stochastic model with a fixed cost of intervention.

27. Note that partial intervention would imply that the exchange rate must change, which, in turn, would imply output losses in sector $y$. Because these losses are costless to avoid through an appropriate intervention (the fixed cost implies that the marginal intervention is costless), partial intervention can never be an optimal policy choice. 
In this case, the representative household's welfare is increasing in $c-\zeta \bar{l}$ $\left(\equiv \hat{W}^{I}\right)$, which is given by

$$
\hat{W}^{I}=B r k_{0}+B \bar{l}^{\eta}-\zeta \bar{l}^{\nu}+B\left(p q^{\theta}-q\right)-B\left(\hat{h}^{2}-\alpha \hat{h}+\kappa\right)-B r \phi,
$$

where we have used the resource constraint (eq. [54]) to substitute out for $c$. The only difference between this expression and the RHS of equation (51) is the cost of intervention term, $B r \phi$, which is independent of all endogenous variables. This establishes our assertion that, if it is optimal to intervene, optimal policy in this instance must coincide with optimal policy under the costless intervention case. For future reference, it is also useful to note that

$$
\frac{d W^{I}}{d \alpha}=\frac{B \alpha}{2}>0,
$$

where we have used the first-order condition given by equation (10), the money demand equation (13), and the fact that the optimal domestic interest rate is independent of $\alpha$. Thus, the smaller the money demand parameter $\alpha$ (i.e., the bigger the shock), the lower the welfare.

\subsubsection{Optimal Policy under No Intervention}

If the policy maker chooses not to pay the cost of intervention, then there will be no intervention at all. Hence, reserves will remain unchanged in response to the money demand shock. In this event, there emerges a role for interest rate policy for domestic macroeconomic management. To see this, consider the case in which the central bank reacts to the negative money demand shock not only by not intervening but also by keeping domestic interest rates unchanged. Money demand falls by the full amount of the shock, whereas domestic loans (and, hence, sector- $x$ output) remain unchanged. With an unchanged nominal stock of government bonds, $\bar{Z}$, equation (53) implies that the nominal exchange rate must increase (because $h$ falls and $n$ does not change). The nominal depreciation along with the nominal wage rigidity implies a fall in the real wage. This causes a contraction of labor supply and output of sector $y$, which returns to the steady-state level only asymptotically.

Now suppose that the central bank raised the domestic interest rate marginally in response to the shock. This would lower loans while reducing the fall in money demand. From equation (53) it is easy to see that, relative to the previous case of unchanged interest rates, the nominal depreciation induced by the shock must be smaller. Accordingly, the fall in the real wage must also be smaller, which in turn implies a smaller contraction of sector $y$. Of course, this benefit comes at the cost of an output contraction in sector $x$, because the credit cost of the imported input is greater. It is clear, however, that in choosing the optimal domestic interest rate policy makers should be trading off these two margins. 
To formalize the government's problem, notice again that welfare is strictly increasing in $c-\zeta\left(l^{s}\right)^{v}\left(\equiv \hat{W}^{N I}\right)$, which takes into account that, for negative money demand shocks, actual employment equals labor supply; that is, $l^{a}=l^{s}$. In the event of no intervention, the economy's resource constraint implies that

$$
\hat{W}^{N I}=B r k_{0}+B\left(p q^{\theta}-q\right)-B\left(\hat{h}^{2}-\alpha \hat{h}+\kappa\right)+r Y,
$$

where $Y=\int_{0}^{\infty}\left[B\left(l_{t}^{s}\right)^{\eta}-\zeta\left(l_{t}^{s}\right)^{v}\right] e^{-r t} d t$ is the present discounted value of sector- $y$ output net of the disutility from labor supply.

At this stage, it is easy to see that the optimal policy problem under intervention becomes more complicated than in the costless intervention case. The reason is that, in response to a depreciation of the currency, the nominal wage rigidity implies that the economy displays intrinsic output dynamics because the labor market goes into disequilibrium. In order to make analytical progress, we simplify the model by setting $\eta=1$ and $\nu=2$. These parameter values make both the production function of sector $y$ and the marginal disutility from labor supply linear in labor. This simplification allows us to compute the change in optimal policies even in the presence of intrinsic output dynamics.

From equation (43), notice that, under linear production in sector $y$, the equilibrium real wage is unity (i.e., $\bar{w}=1$ ), which implies that the nominal wage in the initial steady state must be unity as well. Hence, on impact, the real wage is given by $w_{0}=1 / E_{0}<1$. Moreover, under negative money demand shocks we are restricting attention to $w_{0} \in[0,1]$. From equation (53) it follows that

$$
w_{0}=\frac{h-n}{\bar{Z}} .
$$

Because $h-n$ is increasing in $I^{g}$, it is obvious that the initial real wage is an increasing function of the domestic interest rate. In particular, $\partial w_{0} / \partial I^{g}=$ $(1 / \bar{Z})\left[(1-\delta) / 2 B^{2}-\left(\partial n / \partial I^{g}\right)\right]>0$, whereas $\partial^{2} w_{0} / \partial\left(I^{g}\right)^{2}=-(1 / \bar{Z})\left[\partial^{2} n / \partial\left(I^{g}\right)^{2}\right]<$ 0 . Hence, the initial real wage is an increasing and concave function of the domestic interest rate.

As shown above, an unexpected currency depreciation implies that labor supply is the short end of the labor market. Hence, actual employment is given by labor supply. Under our assumptions on $\eta$ and $\nu$, the actual path of employment, given by equation (48), reduces to

$$
l_{t}^{a}=\bar{l}\left[1+\left(w_{0}-1\right) e^{-\gamma w_{0} t}\right] .
$$

Because employment and labor supply are linear in the initial real wage while $Y=\int_{0}^{\infty}\left[B l_{t}^{a}-\zeta\left(l_{t}^{a}\right)^{2}\right] e^{-r t} d t$, one can differentiate $Y$ with respect to $w_{0}$ to get 


$$
Y_{w}=\frac{\overline{B l}\left(1-w_{0}\right)}{\left(r+2 \gamma w_{0}\right)^{2}}\left[r+\gamma\left(1+w_{0}\right)\right] \geq 0,
$$

where we have used equations (9) and (59) to integrate out over $t$. For later reference, it is useful to note that $\left.Y_{w}\right|_{w_{0}=0}=\left(B \bar{l} \mid r^{2}\right)(r+\gamma)>0$ and $\left.Y_{w}\right|_{w_{0}=1}$ $=0$. It is straightforward to check that $Y_{w w}<0$ for $w_{0} \in[0,1]$.

The policy choices at time zero are $w_{0}\left(=1 / E_{0}\right)$ and $I^{g}$. However, equation (58) makes clear that only one of these two variables can be freely chosen. We shall assume that the policy maker chooses $I^{g}$. Because $\bar{Z}$ is given exogenously and $R_{0}=\bar{R}=0$, a given choice of $I^{g}$ determines $h$ and $n$. These two variables allow us to uniquely determine $w_{0}$ from equation (58). Moreover, all private-sector behavior can be expressed as functions solely of $E_{0}$ and $I^{g}$. Thus, the government's problem can be formalized as choosing $I_{0}^{g}$ to maximize the RHS of equation (57) subject to equations (13), (24), (31), (32), (58), and (59). The first-order condition for this problem is ${ }^{28}$

$$
\begin{aligned}
\frac{d \hat{W}^{N I}}{d I^{g}} \equiv \Gamma^{N I}= & -\frac{B \psi^{2}(p \theta)^{1 /(1-\theta)} I^{g}}{(1-\theta)}\left(\frac{1}{1+\psi I^{g}}\right)^{(2-\theta) /(1-\theta)} \\
& +\frac{(1-\delta)}{2 B} I^{d}+r Y_{w} \frac{\partial w_{0}}{\partial I^{g}} .
\end{aligned}
$$

In the following we shall denote the optimal interest rate for the nointervention case by $I_{N I}^{g}$. Specifically, $\left.\Gamma^{N I}\right|_{I^{8}=I_{N I}^{I}}=0$. Three results follow directly from the first-order condition. First, for $\alpha=1$ the optimal domestic interest rate continues to be $I_{\text {peg }}^{g}$. This can be seen from the fact that $\Gamma^{N I}=0$ for $I^{g}=I_{p e g}^{g}$ and $\alpha=1$. Note that for $I^{g}=I_{\text {peg }}^{g}$ and $\alpha=1$ we must have $w_{0}=$ 1. Because $\left.Y_{w}\right|_{w_{0}=1}=0$, the last term on the RHS of equation (61) drops out. The result then follows from the fact that the first two terms on the RHS are merely $d \hat{W}^{\text {peg }} / d I^{g}$, which is zero for $I^{g}=I_{p e g}^{g}$ (see eq. [52]). Hence, absent a money demand shock, $I_{N I}^{g}=I_{p e g}^{g} \cdot{ }^{29}$

Second, for $\alpha<1$ and $I^{g}=I_{p e g}^{g}$, it is easy to check that $\Gamma^{N I}>0$. Thus, it is optimal for the policy maker to respond to a negative money demand shock by raising the domestic interest rate - that is, $I_{N I}^{g}>I_{p e g}^{g}$. Third, in the case of $\alpha<1$, it is never optimal for the policy maker to raise the domestic interest

28. It is important to note that we will only focus on values of $\psi$ for which there are interior solutions when $\alpha<1$. In general, however, there will be corner solutions. In fact, it is easy to show that, for $\psi=0$ and $\alpha<1$, there will be a corner solution at the $I^{g}$ corresponding to the Friedman rule (i.e., $I^{d}=0$ ). The intuition is clear: If $\psi=0$ and $\alpha<1$, "increasing" $I^{g}$ (if it were possible) above the Friedman rule would have no first-order effects on transactions costs but would have a first-order positive effect on sector- $y$ output as the currency appreciates (i.e., $\Gamma^{N I}$ $>0$, when evaluated at $I^{d}=0$ for $\psi=0$ and $\alpha<1$ ). By continuity, therefore, there will also be corner solutions for very small values of $\psi$. For larger values of $\psi$, interior solutions exist (as we have established using numerical examples).

29. As in the case of costless intervention studied earlier, it can be shown that the condition $\psi r[\delta /(1-\delta)]<1-\theta$ continues to be sufficient (but not necessary) to satisfy the second-order condition. 
rate all the way to the point that $w_{0}=E_{0}=1$. Because $\left.Y_{w}\right|_{w_{0}=1}=0$, this follows from equation (52), which says that the sum of the first two terms on the RHS of equation (61) is negative for $I^{g}>I_{p e g}^{g}$.

Let us now turn to the relationship between the optimal domestic interest rate and the size of the money demand shock. To determine this, we start by noting that, from the implicit function theorem, $d I_{N I}^{g} / d \alpha=-\left(\Gamma_{\alpha}^{N I} / \Gamma_{I^{g}}^{N I}\right)$. Because $-\Gamma_{I^{z}}^{N I}>0$ from the second-order condition, it follows that the signs of $d I_{N I}^{g} / d \alpha$ and $\Gamma_{\alpha}^{N I}$ are the same. Partially differentiating equation (61) with respect to $\alpha$ gives $\Gamma_{\alpha}^{N I}=(r / 2 B \bar{Z})\left(\partial w_{0} / \partial I^{g}\right) Y_{w w}<0$. Hence,

$$
\frac{d I_{N I}^{g}}{d \alpha}=\frac{(r / 2 B \bar{Z})\left(\partial w_{0} / \partial I^{g}\right) Y_{w w}}{-\Gamma_{I^{g}}^{N I}}<0,
$$

which says that the optimal domestic interest rate increases with the size of the shock (i.e., the smaller the value of $\alpha$, and hence the larger the shock, the higher the value of $I_{N I}^{g}$ ).

The next issue of interest is the behavior of the nominal exchange rate as a function of the money demand shock. This is not immediately obvious, because there are two potentially offsetting effects. A fall in $\alpha$ directly reduces money demand and thus, all else being equal, reduces the real wage by increasing $E$. (Recall that $w_{0}=1 / E_{0}=(h-n) / \bar{Z}$ ). However, the fact that the central bank raises interest rates in response to a bigger money demand shock implies that, for a given $\alpha$, money demand rises, which appreciates the currency and raises $w_{0}$. If the latter effect is strong enough, then the nominal exchange rate will fall (i.e., the currency would appreciate) in response to larger shocks.

To shed light on this issue, we totally differentiate equation (58) to get, after some rearrangement,

$$
\frac{d w_{0}}{d \alpha}=\frac{1}{2 \bar{Z} B \Gamma_{I^{g}}^{N I}}\left[\Gamma_{I^{s}}^{N I}-r Y_{w w}\left(\frac{\partial w_{0}}{\partial I^{g}}\right)^{2}\right],
$$

where $\Gamma_{I^{s}}^{N I}$ is the partial derivative of equation (61) with respect to $I^{g}$. As noted above, $\psi r[\delta /(1-\delta)]<1-\theta$ is a sufficient condition to satisfy the second-order condition for welfare maximization (i.e., $\Gamma_{I^{s}}^{N I}<0$ ). It is straightforward to check that this sufficiency condition is also a sufficient condition for $\Gamma_{I^{s}}^{N I}<r Y_{w w}\left(\partial w_{0} / \partial I^{g}\right)^{2} \cdot{ }^{30}$ Hence, $\psi r[\delta /(1-\delta)]<1-\theta$ is a sufficient condition for $d w_{0} / d \alpha>0$, which implies that as $\alpha$ becomes smaller (i.e., the money demand shock gets larger), the initial real wage, $w_{0}$, becomes progressively smaller. Because $E_{0}=1 / w_{0}$, this implies that, with no intervention, the nom-

30. To see this, define $N=p q^{\theta}-q$. Hence, $\Gamma^{N I}=B\left(\partial N / \partial I^{g}\right)+[(1-\delta) / 2 B] I^{d}+r Y_{w}\left(\partial w_{0} / \partial I^{g}\right)$ and $\Gamma_{I^{E}}^{N I}=B\left[\partial^{2} N / \partial\left(I^{g}\right)^{2}\right]-(1-\delta)^{2} / 2 B+r Y_{w w}\left(\partial w_{0} / \partial I^{g}\right)^{2}+r Y_{w}\left[\partial^{2} w_{0} / \partial\left(I^{g}\right)^{2}\right]$. Moreover, $\Gamma_{I^{z}}^{N I}-$ $r Y_{w w}\left(\partial w_{0} / \partial I^{g}\right)^{2}=B\left[\partial^{2} N / \partial\left(I^{g}\right)^{2}\right]-(1-\delta)^{2} / 2 B+r Y_{w}\left[\partial^{2} w_{0} / \partial\left(I^{g}\right)^{2}\right]$. Because $Y_{w w}$ and $\partial^{2} w_{0} / \partial\left(I^{g}\right)^{2}$ are both negative, a sufficient condition for both $\Gamma_{I^{s}}^{N I}<0$ and $\Gamma_{I^{s}}^{N I}<r Y_{w w}\left(\partial w_{0} / \partial I^{g}\right)^{2}$ is $\partial^{2} N / \partial\left(I^{g}\right)^{2}<$ 0 . It is easy to check that $\partial^{2} N / \partial\left(I^{g}\right)^{2}<0$ for $\psi r[\delta /(1-\delta)]<1-\theta$. 
inal exchange rate is a decreasing function of $\alpha$; that is, the larger the negative money demand shock, the larger the currency depreciation.

Finally, it is useful to characterize the welfare effect of a negative money demand shock under the no-intervention regime. Totally differentiating equation (57) with respect to $\alpha$ gives

$$
\frac{d \hat{W}^{N I}}{d \alpha}=\frac{B \alpha}{2}+\frac{r}{2 B \bar{Z}} Y_{w}>0,
$$

where we have used the fact that, at an optimum, the first-order condition for welfare maximization (eq. [61]) says that $\left(\partial \hat{W}^{N I} / \partial I^{g}\right)\left(\partial I_{N I}^{g} / \partial \alpha\right)=0$. We collect these results in the following proposition.

PROPOSITION 4. Under no foreign exchange market intervention, the central bank responds to a negative money demand shock by raising the domestic interest rate while allowing some currency depreciation to occur. Moreover, the larger the negative money demand shock, the larger the increase in the optimal domestic interest rate, the larger the currency depreciation, and the larger the fall in welfare.

\subsubsection{To Intervene or Not To Intervene}

Having described the behavior of optimal interest rate policy contingent on the intervention regime (i.e., intervention or no intervention), we now turn to the determination of the optimal intervention regime itself. For a given $\alpha$, it is straightforward to see that the optimal intervention strategy is determined by

$$
\begin{aligned}
& \text { Do not intervene if }\left.\quad \hat{W}^{N I}\right|_{I^{s}=I_{N I}^{s}}>\left.\hat{W}^{I}\right|_{I^{s}=I_{p e s s}^{p}} \\
& \text { Intervene if }\left.\quad \hat{W}^{N I}\right|_{I^{s}=I_{N I}^{s}} \leq\left.\hat{W}^{I}\right|_{I^{s}=I_{\text {Nox }}^{s e x}}
\end{aligned}
$$

Notice first that around $\alpha=1, \hat{W}^{N I}-\hat{W}^{I}=B r \phi$. This follows from the facts that for $\alpha=1, I_{N I}^{g}=I_{I}^{g}=I_{p e g}^{g}$ and $w_{0}=1$, whereas $l^{s}=l^{a}=\bar{l}$. Intuitively, around $\alpha=1$, the only difference between the two regimes is the cost of intervention, whereas the nominal exchange rate and the domestic interest rates are identical. Consequently, welfare under intervention is lower.

From equations (56) and (63), it is also easy to see that $\left(d \hat{W}^{N I} / d \alpha\right)-$ $\left(d \hat{W}^{I} / d \alpha\right)=(r / 2 B \bar{Z}) Y_{w}>0$. This indicates that although bigger money demand shocks (or lower $\alpha$ 's) cause welfare to decline under both regimes (as indicated by eq. [56] and [63]), welfare under the no-intervention regime falls faster than under the full intervention regime. Intuitively, the direct effect of the money demand shock on transaction costs is the same under the two regimes. However, under the no-intervention regime, a smaller $\alpha$ leads to a lower real wage due to the nominal wage rigidity, which extracts an output cost from sector $y$.

The preceding implies that the relative welfare comparison between the 


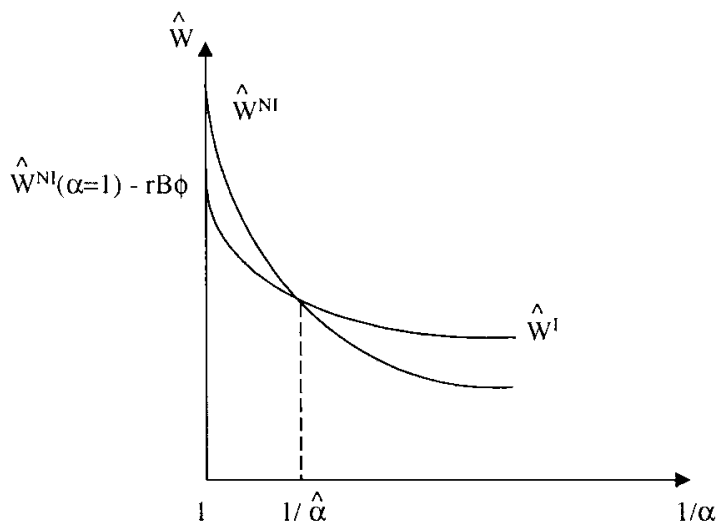

Fig. 14.1 Welfare comparison

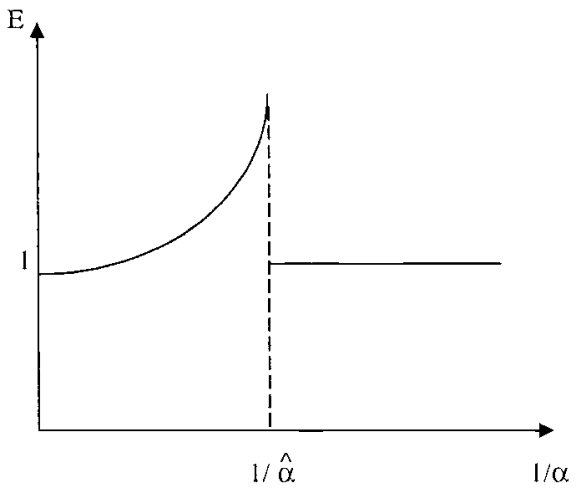

Fig. 14.2 Optimal exchange rate

two regimes reduces to a trade-off between the fixed cost of intervention and the output cost associated with not intervening. Crucially, the output costs under the no-intervention regime increase as the shock grows bigger, but the corresponding cost of intervention is independent of the size of the shock. Hence, the welfare differential between the two regimes shifts in favor of intervention as the shock grows larger. Because $\hat{W}^{N I}-\hat{W}^{I}=B r \phi>0$ around $\alpha=1$, this implies that for a given $\phi$ there must exist a threshold value of $\alpha, \hat{\alpha}<1$, such that $\left.\hat{W}^{N I}\right|_{\alpha=\hat{\alpha}}=\left.\hat{W}^{I}\right|_{\alpha=\hat{\alpha}}$. Further, for all $\alpha<\hat{\alpha}$ we must have $\hat{W}^{N I}<\hat{W}^{I}$. These features of the optimal policy problem are captured in figure 14.1, which depicts welfare under the two regimes as a function of $1 / \alpha$, so that moving to the right along the horizontal axis implies a larger shock (i.e., a smaller value of $\alpha$ ).

Using the above results, one can now completely characterize the optimal policy response to money demand shocks (see table 14.2). For small money 
demand shocks - that is, $\alpha \in(\hat{\alpha}, 1)$ - it is optimal for the policy maker not to intervene but rather let the currency float and raise the domestic interest rate to fight the currency depreciation in order to reduce the resulting output cost. As we saw earlier, this also implies that in this range, the larger the money demand shock, the bigger the currency depreciation. However, for large money demand shocks, (i.e., $\alpha<\hat{\alpha}$ ), it is optimal for the policy maker to keep domestic interest rates unchanged and intervene fully in order to prevent the nominal exchange rate from fluctuating at all. Figure 14.2 depicts the behavior of the nominal exchange rate as a function of $1 / \alpha$. For small shocks (i.e., $1 / \alpha<1 / \hat{\alpha}$ ) the exchange rate is an increasing function of the shock, whereas for large shocks (i.e., $1 / \alpha>1 / \hat{\alpha}$ ) the exchange rate remains fixed (relative to the preshock equilibrium).

The last result worth noting is that the threshold value of the shock parameter, $\hat{\alpha}$, is a decreasing function of the fixed cost of intervention, $\phi$. This result follows from noting that $\left.\left(d \hat{W}^{I I} / d \alpha\right)-\left(d \hat{W}^{I} / d \alpha\right)=(r / 2 B \bar{Z})\right) Y_{w}$ is independent of $\phi$. However, a smaller $\phi$ implies that $\hat{W}^{N I}-\hat{W}^{I}=B r \phi$ is smaller. In terms of figure 14.1, a smaller $\phi$ causes a parallel shift upward of the $\hat{W}^{I}$ schedule, leaving its slope with respect to $\alpha$ unaffected. Hence, the threshold $\hat{\alpha}$ must be larger (i.e., it must be closer to unity). When $\phi=0$, the two schedules coincide for $\alpha=1$, with $\hat{W}^{I}$ exceeding $\hat{W}^{N I}$ for all $\alpha<1$.

We summarize the preceding results in the following proposition.

Proposition 5. The optimal policy response to a negative money demand shock is a function of the size of the shock. For small shocks, it is optimal for the policy maker not to intervene in the foreign exchange market but instead to raise the domestic interest rate and let the currency depreciate. Moreover, in this range, the larger the shock, the higher both the nominal exchange rate and the domestic interest rate. For large shocks, however, it is optimal for the central bank to intervene by the full amount necessary to keep the exchange rate and domestic interest rates unchanged. Furthermore, the smaller the fixed cost of intervention, the smaller the threshold size of the shock for which the full intervention policy becomes optimal.

To assess how well the model might explain the key stylized facts outlined in the introduction, let us perform the following conceptual experiment. Suppose that this economy were subject to a sequence of (stochastic) monetary shocks. Assume, further, that developing countries were hit, on average, by larger shocks than industrial countries. The outcome would be a series of changes in the endogenous policy variables, as captured by the last two rows in table 14.2. From a cross-sectional point of view, the model would predict that developing countries (which face mostly large shocks) would exhibit low exchange rate variability and high reserve variability, whereas developed countries (which face mostly small shocks) would exhibit high exchange rate variability and low reserve variability. From a timeseries perspective, we would observe an average response (because coun- 
tries are hit by both small and large shocks) that would consist (for, say, negative monetary shocks) of falling reserves, a more depreciated currency, and higher interest rates. Hence, the correlation between changes in the exchange rate and interest rates would be positive, but the correlation between (a) reserves and the exchange rate and (b) reserves and interest rates would be negative. All these predictions match the stylized policy facts described in the introduction.

\subsection{Conclusions}

The starting point for this paper has been the observation that, in spite of suffering larger shocks, developing countries (classified as floaters or managed floaters) exhibit lower exchange rate variability and higher reserve variability than developed countries which float. This extreme "fear of floating" is puzzling because, even if nominal exchange rate fluctuations were costly, one would still expect that larger shocks would lead to larger changes in the nominal exchange rate.

This paper has developed a simple and highly stylized theoretical model that is capable of explaining this puzzle. In particular, the model predicts that for small negative money shocks, policy makers find it optimal to let the exchange rate adjust while partly offsetting the shock by raising domestic interest rates. For large shocks, however, policy makers find it optimal to completely stabilize the exchange rate by intervening in the foreign exchange market. The model thus predicts a nonmonotonic relationship between the nominal exchange rate and the size of the shock. If we identify small shocks with developed countries and large shocks with developing countries, the model predicts that developing countries should exhibit low exchange rate variability and high reserve variability, whereas the converse is true for developed countries.

While we view this as a useful first step toward an understanding of the "fear of floating" puzzle, there are at least two directions in which this line of research should be taken. To begin with, we would like to endogenize the fixed cost of intervention, which is of course key to our results. A natural avenue for doing this would be to consider a setup with asset market segmentation along the lines of Alvarez, Atkeson, and Kehoe (1999). Although this would be a major undertaking (given that our focus is on optimal policies, which makes the problem already much more complicated from a formal point of view), it would certainly be worthwhile to pursue. Second, it would be useful to develop a stochastic version of this model, calibrate it for some representative developing country, and try to match the observed correlations. Developing richer models along these lines should prove extremely useful both for understanding the actual responses observed in the data and for devising implementable and usable policy rules for central bankers. 


\section{References}

Agenor, P. R., and J. Aizenman. 1999. Financial sector inefficiencies and coordination failures: Implications for crisis management. NBER Working Paper no. 7446. Cambridge, Mass.: National Bureau of Economic Research.

Aizenman, J., and J. Frenkel. 1985. Optimal wage indexation, foreign exchange intervention, and monetary policy. American Economic Review 75:402-23.

Alvarez, F., A. Atkeson, and P. Kehoe. 1999. Volatile exchange rates and the forward premium anomaly: A segmented asset market view. Federal Reserve Bank of Minneapolis. Mimeograph.

Barro, R., and H. Grossman. 1971. A general disequilibrium model of income and unemployment. American Economic Review 61:82-93.

Burnside, C., M. Eichenbaum, and S. Rebelo. 1999. Hedging and financial fragility in fixed exchange rate regimes. NBER Working Paper no. 7143. Cambridge, Mass.: National Bureau of Economic Research.

Cadenillas, A., and F. Zapatero. 1999. Optimal central bank intervention in the foreign exchange market. Journal of Economic Theory 87:218-42.

Calvo, G., and C. Reinhart. 2000a. Fear of floating. NBER Working Paper no. 7993. Cambridge, Mass.: National Bureau of Economic Research, November.

. 2000b. Fixing for your life. NBER Working Paper no. 8006. Cambridge, Mass.: National Bureau of Economic Research, November.

Calvo, G., and C. Végh. 1995. Fighting inflation with high interest rates: The small open economy case under flexible prices. Journal of Money, Credit, and Banking 27:49-66.

Correia, I., J. Neves, and S. Rebelo. 1995. Business cycles in a small open economy. European Economic Review 39:1089-113.

Drazen, A. 1999a. Interest rate defense against speculative attack under asymmetric information. University of Maryland, Department of Economics. Mimeograph.

- 1999b. Interest rate and borrowing defense against speculative attack. University of Maryland, Department of Economics. Mimeograph.

Druck, P., and P. Garibaldi. 2000. Inflation risk and portfolio allocation in the banking system. University of California, Los Angeles, Department of Economics, and International Monetary Fund. Mimeograph.

Edwards, S. and C. Végh. 1997. Banks and macroeconomic disturbances under predetermined exchange rates. Journal of Monetary Economics 40:239-78.

Flood, R., and O. Jeanne. 2000. An interest rate defense of a fixed exchange rate? International Monetary Fund. Mimeograph.

Lahiri, A., and C. Végh. 2000a. Delaying the inevitable: Optimal interest rate policy and BOP crises. NBER Working Paper no. 7734. Cambridge, Mass.: National Bureau of Economic Research, June.

-2000b. Output costs, BOP crises, and optimal interest rate defense of a peg. University of California, Los Angeles, Department of Economics. Mimeograph.

Levy, E., and F. Sturzenegger. 1999. Classifying exchange rate regimes: Deeds vs. words. Universidad Di Tella, Buenos Aires, Argentina. Mimeograph.

Moron, E., and J. F. Castro. 2000. Uncovering central bank's monetary policy objective: Going beyond fear of floating. Universidad del Pacifico, Lima, Peru. Mimeograph.

Rodriguez, C. A. 1991. Financial reform and macroeconomic developments in Argentina, Chile, and Uruguay during the decade of the 1980s. Universidad del CEMA, Buenos Aires, Argentina. Mimeograph.

Talvi, E., and C. Végh. 2000. Tax base variability and procyclical fiscal policy. 
NBER Working Paper no. 7499. Cambridge, Mass.: National Bureau of Economic Research, January.

\section{Comment Eduardo Borensztein}

This paper by Lahiri and Végh (LV) takes an interesting first step in addressing a very important question, one frequently met when designing monetary or exchange rate policies in emerging markets today. The question is how to respond to a capital outflow, or "exchange market pressure," in an economy with a managed floating exchange rate and an active interest in what happens to the exchange rate. The model is nicely done and clearly presented, but there are some modeling strategy decisions in the monetary and financial area that I do not entirely like.

I like to represent the policy options in a triangle, as in the figure. In the diagram, as we move down, the central bank is intervening more in the foreign exchange market and dampening any adjustment in the exchange rate, perhaps preventing a large depreciation when the country suffers a cutback in external financing or an outflow of capital.

At the top vertex of the triangle, we are in a clean float, with no central bank intervention at any time. Along the bottom of the triangle, the exchange rate is completely fixed, and the adjustment to a negative external shock comes fully through a loss in international reserves. However, here there is another dimension of policies, namely the extent to which the central bank sterilizes the monetary effect of a loss in reserves by creating domestic credit. At one extreme there is no attempt to sterilize, and the fall in reserves is fully reflected in the monetary base (and in domestic interest rates). In this vertex, the central bank would be operating as a (textbook) currency board. At the other extreme, the central bank completely sterilizes the monetary impact of its intervention in the foreign exchange market, allowing domestic monetary conditions to remain undisturbed.

Suppose there is a shock to external financing, say because of contagion. Which point in this triangle is it optimal to choose? Intuition would suggest some interior point in the triangle, avoiding the financial-sector distress that can come from excessive depreciation or too high interest rates and the fiscal implications of, and perhaps also market constraints on, sterilized intervention on a large scale. ${ }^{1} \mathrm{LV}$, while not intentionally attempting to rep-

Eduardo Borensztein is chief of the developing countries studies division of the International Monetary Fund research department.

1. This implicitly ignores arguments about the institutional strength or credibility of a legally established regime such as a currency board. 


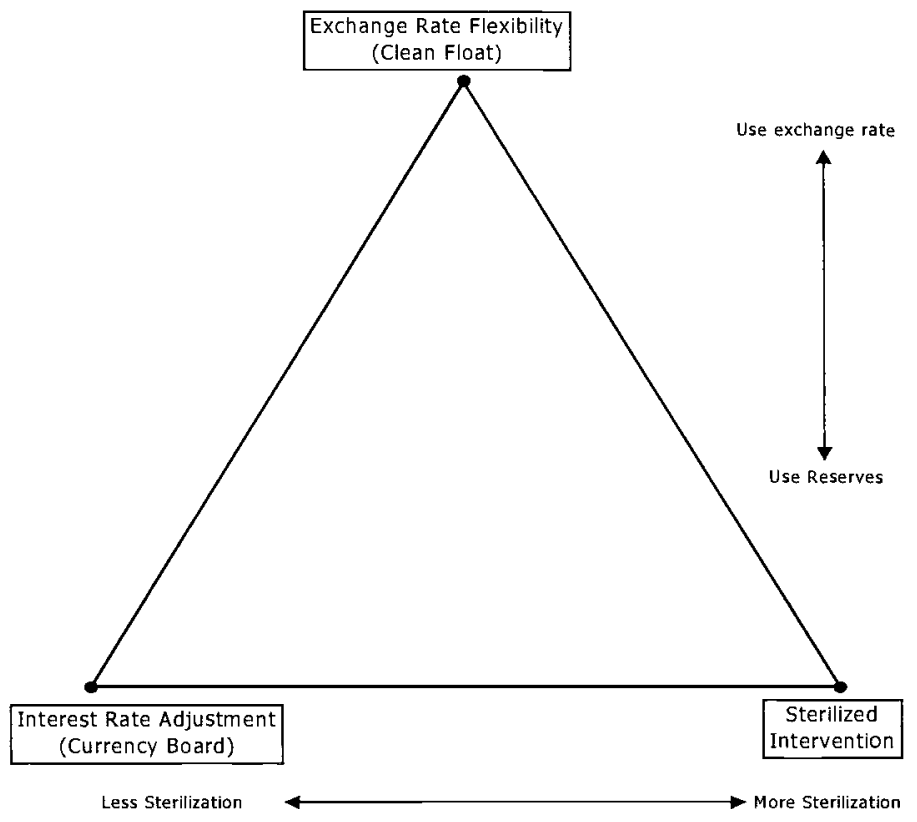

Fig. 14C.1 Response to exchange market pressure

resent the above story, find that countries should choose an interior point in the triangle, at least for large shocks.

The results in LV can be easily summarized. In what concerns the extent of exchange rate flexibility (the choice along the vertical direction in the diagram) in the basic framework with wage rigidity but no cost of foreign exchange intervention, traditional results apply: for monetary shocks, a constant exchange rate is superior, and for real shocks the opposite holds - namely, a full adjustment in the exchange rate is preferable. The basic reason is that, in each case, those are the regimes that will allow real wages to stay at or near their equilibrium levels. LV then introduce a fixed cost to foreign exchange market intervention by the central bank. With this cost, the optimal response to a shock to a somewhat idiosyncratic money demand (more on this later) depends on the size of the shock. For small changes, the cost of intervention is too high, and it is preferable to let the exchange rate adjust fully. For sufficiently large shocks to money demand, however, it is optimal to intervene, and we return to the standard result of keeping the exchange rate fixed and using reserves to the full extent necessary.

The main weakness that I find in the LV framework is that all the relevant domestic interest rates (on bank deposits and loans and on government bonds) are not related to the international interest rate, the expected depreciation of the exchange rate, or the country risk premium because they cor- 
respond to assets that are "nontraded" by assumption. That is, the kind of transactions that individuals, firms, and the government can perform preclude any competition between domestic and foreign financial assets. Although I understand that the model would become too complicated if these assets were "traded," I would happily give up the careful, first-principles, infinite-horizon detail in the consumer and real sectors in exchange for a less crude financial-sector framework. Particularly when considering the apparent puzzle of limited exchange rate variability in emerging-market economies, as this paper sets out to do, it seems important to try to incorporate the reaction of the central bank to changes in country risk, credibility, and the like.

Money demand is also special. It is the demand for an interest-bearing demand deposit used for transactions, and thus it depends positively on the interest rate. It is somewhat difficult to interpret money demand shocks in this framework. Do they approximate a "capital outflow" that is reversed when domestic interest rates increase? The framework also does not permit differentiation between money demand and "bond demand," that is, between liquidity conditions and the demand for government and private liabilities that reflects considerations of risk premium and so on. Once again, in view of the exchange rate variability puzzle that motivates the paper, it is not clear how relevant these LV money demand shocks are in explaining the contrast between emerging markets and advanced economies in their management of exchange rates.

As concerns the extent of sterilization of the monetary impact of changes in international reserves (the choice along the horizontal direction of the triangle), the results are less easy to interpret. It is not entirely clear what sterilization of a money demand shock should mean. Central banks sterilize to avoid the monetary impact of a change in reserves generated by some current account or capital account shock. However, the shock considered in the paper originates in domestic monetary and financial markets themselves. In any event, when the optimal policy involves foreign exchange market intervention by the central bank, it also involves expanding domestic credit so that domestic interest rates remain constant. LV define a "fully sterilized intervention" policy as one that always keeps the real quantity of money constant, which seems appropriate in general. For this particular shock, however, the optimal policy comes close to what one could think of as full sterilization, keeping interest rates and the level of bank loans constant, although the level of deposits (money demand) declines. 


\section{Discussion Summary}

Sebastian Edwards commented on the policy options that a country may choose from when facing external shocks. The optimal policy is probably some combination of the three instruments - higher interest rates, sterilized intervention, and exchange rate flexibility —inside the "triangle" that Eduardo Borensztein showed. Roberto Chang and Andrés Velasco's paper derives formally a similar result, but Edwards was concerned with how useful this type of result is to policy makers. Drawing on the recent experience of Mexico, he proposed to analyze the trigger strategy for interest rate intervention. The Mexican authorities selected the upper corner of the triangle and are floating the exchange rate without using any other policy most of the time. However, when shocks surpass some threshold, that triggers the use of another policy, namely, interest rate intervention. This policy arrangement is highly asymmetrical, but it has worked. For example, when peso intraday trading against the dollar reached 11 in September 1998, the authorities increased the interest rate to about 55 percent and suspended the CETES auction. When things calmed down, however, they stopped using interest rate policy and returned to the corner of floating the exchange rate. The question to those at the table was what the likelihood is of generating this kind of model and evaluating this kind of policy. This is what policy makers are looking for.

Federico Sturzenegger made the remark that in the model any change of interest rates will lead to a loss of output, which leads to a bias toward fixed exchange rates. To circumvent this effect, the model then imposes the unnatural cost of intervention. An alternative method would be to allow for the benefits from a flexible exchange rate, which is a much more plausible specification.

Jaume Ventura commented on the way the model generates a fear-offloating exchange rate through nominal wage rigidity. The standard Friedman argument is that when there is nominal wage rigidity, there is a fear of fixed rates, and the exchange rate must equate the labor market. Thus, if one thinks that most shocks to an economy affect labor demand and labor supply, then the floating exchange rate is really better, because it can be used to keep the real wage at the level where it should be. This is true in the model, but the paper focuses on discussing the effects of a shock to money demand, which is why things are reversed. Because real wage should never change, one should avoid as much as possible a change in the exchange rate. There are two problems. First, one has to make an assessment of the kinds of shocks an economy goes through: are most shocks hitting the labor market or money demand? Depending on the answer, one can choose one policy or another. Second, even if the shocks to money demand are very important, one wants to fix the interest rate, as most standard results suggest. This is 
not the case here because the paper does not allow for sterilization. However, if sterilization is not very costly, then nominal wage rigidity cannot be a convincing channel to create the fear of floating.

Alejandro M. Werner said that central bankers who float their currencies and use interest rate policy are not concerned with money demand shocks - they can always adjust money supply at a given interest rate. Thus, the important shocks to the monetary authorities are real shocks and portfolio shocks.

Enrique G. Mendoza raised this question: how strong is the assumption that domestically issued bonds cannot be traded? He also commented on the assumption that firms use credit from the banking system to buy imports, and asked whether similar results would hold if firms could use foreign loans instead.

Amartya Lahiri agreed that the paper took an extreme stand on the validity of interest rate policy; however, he said, other approaches (for example, Flood and Ventura's portfolio model approach) lead to similar results. The key feature is how the risk premium between the domestic and foreign interest rates changes with policies. He said that other modeling strategies are feasible and can handle the sterilization interventions, which they are working on.

Lahiri also agreed with Ventura that in the case of a real shock, one should allow the exchange rate to float. The authors plan to calibrate both monetary and real shocks and determine whether the model can produce the moments that they find in the data on exchange rate and interest rate fluctuations.

He also said that the paper focused on money demand shocks because this was the easiest way to create an environment with a capital outflow and a depreciation pressure on the currency. He asked the audience not to take this aspect of the model very seriously.

Carlos A. Végh agreed with discussant Borensztein that the optimal policy choice should lie inside the triangle. He said that the model could be easily generalized (by introducing imperfect substitutability between domestic and foreign assets) to have this result. On the issue of monetary shocks, he pointed out that in this model shocks to money demand should be interpreted as portfolio shocks because the monetary aggregate in the model is in the spirit of saving accounts. 
